\title{
Synthesis of graphene oxide-quaternary ammonium nanocomposite with synergistic antibacterial activity to promote infected wound healing
}

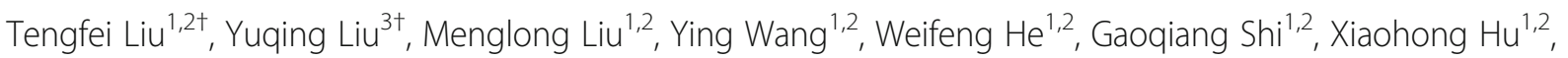
Rixing Zhan ${ }^{1,2}$, Gaoxing Luo ${ }^{1,2^{*}}$, Malcolm Xing ${ }^{1,3^{*}}$ and Jun $\mathrm{Wu}^{1,4^{*}}$

\begin{abstract}
Background: Bacterial infection is one of the most common complications in burn, trauma, and chronic refractory wounds and is an impediment to healing. The frequent occurrence of antimicrobial-resistant bacteria due to irrational application of antibiotics increases treatment cost and mortality. Graphene oxide (GO) has been generally reported to possess high antimicrobial activity against a wide range of bacteria in vitro. In this study, a graphene oxide-quaternary ammonium salt (GO-QAS) nanocomposite was synthesized and thoroughly investigated for synergistic antibacterial activity, underlying antibacterial mechanisms and biocompatibility in vitro and in vivo.

Methods: The GO-QAS nanocomposite was synthesized through amidation reactions of carboxylic group end-capped QAS polymers with primary amine-decorated $\mathrm{GO}$ to achieve high QAS loading ratios on nanosheets. Next, we investigated the antibacterial activity and biocompatibility of GO-QAS in vitro and in vivo.

Results: GO-QAS exhibited synergistic antibacterial activity against bacteria through not only mechanical membrane perturbation, including wrapping, bacterial membrane insertion, and bacterial membrane perforation, but also oxidative stress induction. In addition, it was found that GO-QAS could eradicate multidrug-resistant bacteria more effectively than conventional antibiotics. The in vitro and in vivo toxicity tests indicated that GO-QAS did not exhibit obvious toxicity towards mammalian cells or organs at low concentrations. Notably, GO-QAS topically applied on infected wounds maintained highly efficient antibacterial activity and promoted infected wound healing in vivo.

Conclusions: The GO-QAS nanocomposite exhibits excellent synergistic antibacterial activity and good biocompatibility both in vitro and in vivo. The antibacterial mechanisms involve both mechanical membrane perturbation and oxidative stress induction. In addition, GO-QAS accelerated the healing process of infected wounds by promoting re-epithelialization and granulation tissue formation. Overall, the results indicated that the GO-QAS nanocomposite could be applied as a promising antimicrobial agent for infected wound management and antibacterial wound dressing synthesis.
\end{abstract}

Keywords: Graphene oxide, Quaternary ammonium salt, Antibacterial activity, Synergistic effect, Antibiotic resistance, Wound healing

\footnotetext{
*Correspondence: logxw@yahoo.com; malcolm.xing@umanitoba.ca; junwu@burninchina.com

${ }^{\dagger}$ Tengfei Liu and Yuqing Liu contributed equally to this work.

${ }^{1}$ Institute of Burn Research, State Key Laboratory of Trauma, Burn and

Combined Injury, Southwest Hospital, Third Military Medical University (Army

Medical University, Chongqing, China

Full list of author information is available at the end of the article
}

(c) The Author(s). 2018 Open Access This article is distributed under the terms of the Creative Commons Attribution 4.0 International License (http://creativecommons.org/licenses/by/4.0/), which permits unrestricted use, distribution, and reproduction in any medium, provided you give appropriate credit to the original author(s) and the source, provide a link to the Creative Commons license, and indicate if changes were made. The Creative Commons Public Domain Dedication waiver (http://creativecommons.org/publicdomain/zero/1.0/) applies to the data made available in this article, unless otherwise stated. 


\section{Background}

Antibiotics have saved countless lives since their first appearance. However, the prevalence of antimicrobialresistant bacteria, caused by the indiscriminate application and overuse of antibiotics, has been a global issue threatening human health for the past several decades [1]. Antimicrobial resistance is projected to cause the death of approximately 300 million people in the next 35 years [2]. Wound infection with antimicrobialresistant bacteria aggravates wound deterioration, delays wound healing, and even causes sepsis and death [3]. Thus, it is imperative for us to find alternative ways to prevent and treat wound infection to restore the normal microenvironment for wound healing.

In recent years, graphene oxide (GO) nanosheets have drawn much attention due to their excellent antibacterial activity [4-6]. Several reports have claimed that GObased nanocomposites, whether topically applied on wounds as antibacterial agents [7] or incorporated into dressing scaffolds as antibacterial wound dressings $[8,9]$, can significantly facilitate wound healing by eradicating bacteria in wounds. GO, a derivative of graphene, is a two-dimensional one-atom-thick sheet composed of $\mathrm{sp}^{2}$-hybridized carbon atoms [10]. The observed antimicrobial properties of GO have been attributed to the combined mechanisms of bacterial membrane perturbation caused by sharp edges and oxidative stress induction [11, 12]. Additionally, an abundance of functionalized hydroxyl, epoxy, and carboxyl groups on the graphene oxide surface enhance its hydrophilicity and biocompatibility and significantly facilitate its surface modification with other molecules or polymers $[4,5,10]$. However, owing to the presence of strong interplanar interactions, graphene oxide is prone to aggregate in aqueous solutions in a layer by layer manner, which potentially limits its application [13, 14]. Furthermore, there is currently no consensus regarding the intrinsic antibacterial properties of bare graphene oxide [15, 16]. Different reports claim that $\mathrm{GO}$ possesses strong [4, 11], very weak [17], or no [18] antimicrobial activity, or even facilitates bacterial proliferation [19]. Therefore, it is necessary to prepare functionalized graphene oxide derivatives to consolidate the antibacterial activity of graphene oxide and make it more stable in aqueous solutions.

Currently, there are several reports on avoiding graphene oxide aggregation by grafting certain materials, such as polydopamine [20], $\mathrm{Fe}_{3} \mathrm{O}_{4}$ [21], and silver nanoparticles (AgNPs) [22, 23]. However, the cytotoxicity of AgNPs is a matter of concern [24]. Quaternary ammonium salts (QAS) are other commonly utilized bactericides that exhibit strong antibacterial activity [25-27]. The general antibacterial mechanism of QAS is believed to be associated with adsorption on the cell wall through electrostatic interactions, which subsequently increases membrane permeability and disrupts the membrane [25-27]. Two-dimensional GO nanosheets have an intrinsically high surface area to volume ratio and therefore could be an ideal nanocarrier platform to load QAS at a high density, allowing a larger contact interface with bacteria to advance the antibacterial performance [28]. Moreover, QAS can also be used as cationic surfactants to facilitate dispersion of GO nanocarriers [27]. It is worthwhile to explore the enhanced antimicrobial effects of graphene oxide-quaternary ammonium salts (GOQAS) nanocomposites. Recently, Ye et al. reported the synthesis of graphene oxide/reduced graphene oxideQAS nanocomposites with significant antibacterial activity through $\pi-\pi$ conjugations $[29,30]$. Tu et al. reported a click synthesis of a GO-quaternized poly(dimethylaminoethyl methacrylate) nanocomposite coating with good antibacterial and antifouling ability [31]. Despite these reports concerning the synthesis of GO-QAS with good antibacterial activity, it is still unclear whether GO-QAS has an advantage as a new antibacterial nanomaterial weapon with unique or synergistic efficiency compared with the simple combination of separate GO and QAS, and the detailed antibacterial mechanisms of GO-QAS nanocomposites are still unknown. In addition, little is known about the biocompatibility and antibacterial activity of GO-QAS in vivo.

To address these questions, in this work, GO-QAS nanocomposites were synthesized through amidation reactions of carboxylic group end-capped QAS polymers with primary amine-decorated GO to achieve high QAS loading ratios on nanosheets, and we investigated, for the first time, the synergistic antibacterial activity of GO-QAS and the underlying antibacterial mechanisms. We demonstrated that compared with pure GO, QAS or the simple mixture of GO and QAS, GO-QAS with an optimal QAS graft ratio exhibited significantly enhanced and synergistic antibacterial activity. The antibacterial mechanisms of GO-QAS involved not only mechanical bacterial membrane perturbation, including wrapping, bacterial membrane insertion, and bacterial membrane perforation, but also oxidative stress induction. In addition, GO-QAS exhibited significant antibacterial activity against Methicillin-resistant Staphylococcus aureus (MRSA) and multidrug-resistant Acinetobacter baumanii (MDR-AB). Furthermore, we demonstrated the good biocompatibility of GO-QAS both in vitro and in vivo. Moreover, when topically applied on infected wounds in vivo using a murine-infected full-thickness skin defect wound model, GO-QAS could eradicate pathogenic bacteria on wounds and facilitate the healing of infected wounds. To the best of our knowledge, this study represents the first systematic investigation of the 
antimicrobial and biocompatibility properties of GOQAS both in vitro and in vivo. We expect our research to provide an in-depth understanding of the antibacterial behaviors and biocompatibility of GO-QAS and to serve as a practical reference for GO-QAS-based antibacterial wound dressings or antifouling coating materials research.

\section{Methods}

\section{Materials}

GO powder (1-5 layers, $95 \mathrm{wt} \%$, specific area 300$450 \mathrm{~m}^{2} / \mathrm{g}$ ) was purchased from Suzhou Tanfeng Ltd. (Suzhou, China). Double deionized water (DD water) was purified with a Millipore Q3 instrument. LIVE/ DEAD $^{\text {tw }}$ BacLight $^{\text {tm }}$ Bacterial Viability kit (L7012, Molecular Probes, Invitrogen) was purchased from Thermo Fisher Scientific (Life Technologies, USA). All other chemicals were purchased from Sigma-Aldrich and used directly.

BALB/c mice (male, 20-25 g) were purchased from the Experimental Animal Department of the Army Medical University (Chongqing, China) and were raised individually in plastic cages under standardized conditions (room temperature: $25{ }^{\circ} \mathrm{C}$; relative humidity: $50 \%$; and circadian rhythm: $12 \mathrm{~h}$ ) for 2 weeks before the experiment, with free access to autoclaved standard rodent chow and water. All the animal experiments (including in vivo biosafety, antibacterial activity, and infected wound healing evaluation) were approved by the Institutional Animal Care and Use Committee of the Third Military Medical University.

\section{Synthesis of graphene oxide-quaternary ammonium salts nanocomposite \\ Synthesis of S-dodecyl-S'-(a, $a^{\prime}$-dimethyl-a"-acetic acid) trithiocarbonate (RAFT-COOH)}

Synthesis of the RAFT-COOH chain transfer agent was in accordance with previously published literature [32].

\section{Synthesis of (2-(acryloyloxy)ethyl)-N,N-dimethylhexa- ammonium bromide (AEDMHA)}

The quaternary ammonium salt monomers were prepared by quaternization of 1-bromohexane with 2(dimethylamino)ethyl acrylate (DMAEA). Briefly, $1.43 \mathrm{~g}$ DMAEA (10 mmol) and $1.98 \mathrm{~g}$ 1-bromohexane (12 mmol) were added into a $25 \mathrm{~mL}$ round-bottom flask filled with $10 \mathrm{~mL}$ of acetonitrile $(\mathrm{MeCN})$, and the solution was heated at $80{ }^{\circ} \mathrm{C}$ for $16 \mathrm{~h}$. The reaction was quenched by soaking in an ice water bath. Most of the solvent was removed by rotational evaporation, and $20 \mathrm{~mL}$ of ethyl ether was added into the flask to wash the mixture. AEDMHA was crystallized at $4{ }^{\circ} \mathrm{C}$, filtered and rinsed with cold ethyl ether. The pale powder was recovered by drying in a vacuum oven overnight, with a yield of $\sim 2.6 \mathrm{~g}$.

\section{RAFT polymerization of AEDMHA quaternary ammonium salt (PAEDMHA)}

Briefly, $1.5 \mathrm{~g}$ AEDMHA monomer, $68.3 \mathrm{mg}$ RAFT$\mathrm{COOH}, 6.2 \mathrm{mg}$ azobisisobutyronitrile (AIBN), and $5 \mathrm{~mL}$ of $\mathrm{MeCN}$ were added into a $10 \mathrm{~mL}$ round-bottom flask sealed with a rubber septum to target an average molecular weight of $8 \mathrm{kDa}$. The solution was degassed by nitrogen sparging for $20 \mathrm{~min}$ and stirred at $60{ }^{\circ} \mathrm{C}$ for $20 \mathrm{~h}$. After the reaction, a small portion of the solution was collected, dried under vacuum, and used for measuring polymerization conversion via ${ }^{1} \mathrm{H}$ nuclear magnetic resonance (NMR) spectroscopy. The product was precipitated out of tetrahydrofuran (THF) twice for purification and recovered from drying under vacuum as a light-yellow powder with a yield of $1.05 \mathrm{~g}$.

\section{Amine-grafted graphene oxide (GO-NH$)$ via silanization}

The salinization of GO was conducted in dimethylformamide (DMF). Briefly, $150 \mathrm{mg}$ of $\mathrm{GO}$ powder was mixed with $40 \mathrm{~mL}$ DMF and $1.2 \mathrm{~mL}$ DD water. The mixture was dispersed using a probe sonic homogenizer (SK92-IIN ultrasonicator, maximum output power $650 \mathrm{~W}, 20-25 \mathrm{kHz}$ ) with an output of $50 \%$, in an ice bath for $2 \mathrm{~h}$. After sonication, there were no visible particles of GO in the mixture. Then, $0.6 \mathrm{~mL}$ of (3-aminopropyl)trimethoxysilane (APTMS) was added into the mixture under nitrogen protection. The dispersion was stirred at $60{ }^{\circ} \mathrm{C}$ for $15 \mathrm{~h}$, and the dispersed mixture became very viscous after the reaction. $\mathrm{GO}-\mathrm{NH}_{2}$ was precipitated out of ethanol, collected via centrifugation, and repeatedly washed with ethanol. The product was dispersed in water and dialyzed against DD water with dialysis tubing (molecular weight cutoff $(\mathrm{MWCO})=$ $12 \sim 14 \mathrm{kDa}$ ) for 3 days, followed by lyophilization. Dark gray powder was collected with a yield of $\sim 350 \mathrm{mg}$.

\section{Preparation of quaternary ammonium salt polymer- modified $G O$}

PAEDMHA polymers were grafted onto GO- $\mathrm{NH}_{2}$ nanosheets via an amidation reaction with different grafting ratios, and the feeding ratios (mass) of GO- $\mathrm{NH}_{2}$ : PAEDMHA were 1:2, 1:4, 1:8, and 1:16, respectively, for GO-QAS-1, GO-QAS-2, GO-QAS-3, and GO-QAS-4. In the typical reaction of GO-QAS-3, $100 \mathrm{mg}$ of GO-NH powder, $800 \mathrm{mg}$ of PAEDMHA polymer, and $40 \mathrm{~mL}$ of DD water were mixed together and sonicated using a probe sonic homogenizer for $3 \mathrm{~h}$ under the same conditions described above. To the dispersed mixture, $33.2 \mathrm{mg}$ of 1-ethyl-3-(3-dimethylaminopropyl)carbodiimide hydrochloride (EDC) and $20.2 \mathrm{mg}$ of N-hydroxysuccinimide (NHS) were added. Then, the dispersion was stirred at 
ambient temperature for 2 days. The mixture was further sonicated for $30 \mathrm{~min}$ after the first 24-h reaction. After the reaction, the dispersion was dialyzed against $\mathrm{DD}$ water with dialysis tubing ( $\mathrm{MWCO}=12 \sim 14 \mathrm{kDa}$ ) for 3 days to remove unconjugated polymers, and the final product GO-poly (AEDMHA) was recovered by lyophilization with a yield of $535 \mathrm{mg}$ as a dark gray powder. For other reactions, the ratio of GO-NH $\mathrm{N}_{2}$ :PAEDMHA changed, but the ratio of PAEDMHA:EDC/NHS was kept the same. The product yields and estimated grafted ratios are presented in Table S1 (see Additional file 1). For convenience, GO-QAS was used to denote GO- poly (AEDMHA) in our article.

\section{Characterization}

Nuclear magnetic resonance (NMR). All ${ }^{1} \mathrm{H}$ NMR tests were carried out on a Bruker Avance $300 \mathrm{MHz}$ NMR spectrometer using $\mathrm{CDCl}_{3}$ or $\mathrm{D}_{2} \mathrm{O}$ as the solvent at a concentration of $10 \mathrm{mg} / \mathrm{ml}$, with 32 scans and a relaxation delay $(\mathrm{d} 1)$ set to $1 \mathrm{~s}$.

Fourier transform infrared (FTIR) spectroscopy. FTIRATR (attenuated total reflection) characterizations were conducted on a Nicolet iS10 FTIR spectrometer, with 32 scans and a resolution of 4 .

Atomic force microscopy (AFM). The thickness of GO and GO-QAS nanosheets was characterized by AFM. Briefly, a single drop of dispersion was spread on the surface of freshly cut mica and air-dried prior to AFM analysis.

Scanning electron microscopy (SEM). Briefly, single drops of GO and GO-QAS dispersions were drop-cast onto a clean silicon wafer and air-dried. Then, samples were $\mathrm{Au}$ sputter-coated for $60 \mathrm{~s}$ before SEM imaging (Zeiss Crossbeam 340, Germany).

Transmission electron microscopy (TEM). The morphology of GO and GO-QAS nanosheets was characterized by TEM. Briefly, a drop of the prepared dispersion was deposited on a carbon-coated copper grid and air-dried preceding TEM (JEOL JEM-1400, Japan) analysis.

Dynamic light scattering (DLS). The particle size distribution of GO and GO-QAS was determined with a particle size analyzer (Malvern Zetasizer Nano ZS90, Britain). A refractive index $(n=1.3)$ matching the filtered $(0.2 \mu \mathrm{m})$ bath surrounded the scattering cell, and the temperature was fixed at $25{ }^{\circ} \mathrm{C}$. Three independent measurements were performed for each sample.

Zeta potential measurements. Zeta potential measurements of GO and GO-QAS dispersions at $50 \mu \mathrm{g} / \mathrm{mL}$ in deionized (D.I.) water were performed on a zetapotential analyzer (Malvern Zetasizer Nano ZS90, Britain) at $25{ }^{\circ} \mathrm{C}$. Each measurement was repeated at least three times.

Thermogravimetric analysis (TGA). TGA was conducted using a TGA Q500 thermogravimetric analyzer from room temperature to $600{ }^{\circ} \mathrm{C}$ at a heating rate of 10 ${ }^{\circ} \mathrm{C} / \mathrm{min}$ under a nitrogen atmosphere. All samples were completely dried under vacuum without heating and stored in a desiccator before the test.

\section{Antimicrobial activity investigation Bacterial cells and nanocomposite preparations}

Four representative bacterial species, Staphylococcus aureus (S. aureus, ATCC 25923), Escherichia coli (E. coli, ATCC 25922), MRSA (ATCC 43300), and a clinically isolated MDR-AB, were chosen as model gram-positive and gram-negative bacteria in the present study. Briefly, a single isolated colony of bacteria on a solid LuriaBertani (LB) agar plate was transferred to $5 \mathrm{~mL}$ of $\mathrm{LB}$ broth medium and grown overnight at $37{ }^{\circ} \mathrm{C}$ under $200 \mathrm{rpm}$ rotation. Then, the bacteria culture medium was centrifuged at $6000 \mathrm{rpm}$ for $5 \mathrm{~min}$, and the bacterial pellet was subsequently washed three times with deionized water to remove medium constituents and other chemical macromolecules [33]. Afterwards, the pellet was resuspended in deionized water, and the optical density (OD) value of the suspension was adjusted to 0.5 at $600 \mathrm{~nm}$, which corresponded to a concentration of $10^{8}$ colony-forming units per milliliter $(\mathrm{CFU} / \mathrm{mL})$. The stock dispersions of all the nanocomposites were prepared at a concentration of $1 \mathrm{mg} / \mathrm{mL}$ and then diluted to certain concentrations. All the nanocomposite dispersions were sterilized by UV radiation for $30 \mathrm{~min}$ preceding experiments.

\section{Influence of the QAS graft ratio on the antibacterial activity of GO-QAS}

To determine the optimal QAS graft ratio at which the GO-QAS nanocomposite exhibited the strongest antibacterial activity, we investigated the antibacterial activity of GO-QAS with diverse QAS graft ratios using the plate count method as previously reported [34]. Briefly, $200 \mu \mathrm{L}$ aliquots of $E$. coli and S. aureus bacteria suspensions at $0.5 \mathrm{OD} 600_{\mathrm{nm}}$ in deionized water were mixed with $20 \mu \mathrm{L}$ of GO-QAS dispersions with diverse QAS graft ratios at $50 \mu \mathrm{g} / \mathrm{mL}$ concentrations (GO-QAS1; GO-QAS-2; GO-QAS-3; GO-QAS-4) and then incubated at $37{ }^{\circ} \mathrm{C}$ for $3 \mathrm{~h}$ with constant shaking at $200 \mathrm{rpm}$. Control samples were prepared with $200 \mu \mathrm{L}$ cell suspensions and $20 \mu \mathrm{L}$ deionized water. After $3 \mathrm{~h}$, serial 10 -fold dilutions of cells were spread onto LB plates and left to grow overnight at $37{ }^{\circ} \mathrm{C}$. Colonies were counted, and the numbers were compared with control plates to calculate the cell viability rate. All treatments were prepared in triplicate and repeated on three separate occasions. The cell viability rate was calculated based on the following formula: cell viability $\%=$ counts of test samples/counts of control $\times 100 \%$. 


\section{Antibacterial activity of the optimized GO-QAS nanocomposite at different concentrations}

Agar diffusion test The inhibition zone of GO-QAS at different concentrations was determined by an agar diffusion test as previously reported, with some modifications [35]. Briefly, $100 \mu \mathrm{L}$ of bacterial suspensions $\left(10^{8} \mathrm{CFU} / \mathrm{mL}\right)$ of $S$. aureus and $E$. coli were uniformly spread on the surface of Muller Hinton agar plates with sterile cotton swabs. Then, six wells (diameter of $6 \mathrm{~mm}$ ) were made on each test plate with the help of a sterile borer. Samples $(50 \mu \mathrm{L})$ of GO and GO-QAS dispersions at different concentrations (from 5 to $200 \mu \mathrm{g} / \mathrm{mL}$ ) were introduced into the peripheral five wells. An equal volume of streptomycin sulfate $(1 \mathrm{mg} / \mathrm{mL})$ was loaded in the central well to serve as the positive control. Then, all the plates were incubated at $37{ }^{\circ} \mathrm{C}$ overnight. The antimicrobial activity was observed as transparent halos surrounding the well.

Plate count method The plate count method was performed to determine the antibacterial activity of $\mathrm{GO}$, QAS, and GO-QAS dispersions at different concentrations as mentioned above. Briefly, $200 \mu \mathrm{L}$ of cell suspension was mixed with $20 \mu \mathrm{L}$ of different concentrations of GO, QAS, and GO-QAS dispersions (i.e., 50, 100, and $200 \mu \mathrm{g} / \mathrm{mL}$ ) and then incubated for $3 \mathrm{~h}$ at $37{ }^{\circ} \mathrm{C}$ under $200 \mathrm{rpm}$ rotation. Deionized water was used as the control. After $3 \mathrm{~h}$, diluted cells were spread onto LB plates and left to grow overnight at $37{ }^{\circ} \mathrm{C}$. Colonies were counted, and the numbers were compared with control plates to calculate the cell viability rate.

Bacterial live/dead viability assay The antibacterial activity of GO, QAS, and GO-QAS was further verified with a bacterial live/dead viability assay [36]. The dyes SYTO 9 and propidium iodide (PI) were used according to the manufacturer's instructions. Briefly, $200 \mu \mathrm{L}$ of cell suspension was mixed with $20 \mu \mathrm{L}$ of GO, QAS, or GOQAS dispersions at $200 \mu \mathrm{g} / \mathrm{mL}$ concentration (selected based on the highest antimicrobial activity) or control (sterile deionized water). The mixture was incubated at $37{ }^{\circ} \mathrm{C}$ for $3 \mathrm{~h}$ at $200 \mathrm{rpm}$. Then, cells were harvested by centrifugation in a microcentrifuge tube at $6000 \mathrm{rpm}$ and resuspended in $1 \mathrm{~mL}$ of sterile deionized water. Then, the suspensions were stained with SYTO $9(3 \mu \mathrm{L})$ and PI $(3 \mu \mathrm{L})$ for $15 \mathrm{~min}$ in the dark. Afterwards, a $2 \mu \mathrm{L}$ aliquot of stained suspension was dropped on a clean glass slide and imaged under a laser confocal microscope (Zeiss LSM780, Germany). The cell death percentage is expressed as the number of dead cells (in red)/the number of total cells (in green) $\times 100 \%$.
Investigation of the synergistic antibacterial effect of GO-QAS The synergistic antibacterial effect of GO-QAS was investigated using the plate count method as previously reported [37]. S. aureus and E. coli bacteria cells were treated with dispersions of $8 \mu \mathrm{g} / \mathrm{mL}$ GO, $81.3 \mu \mathrm{g} / \mathrm{mL}$ QAS, a mixture of $8 \mu \mathrm{g} / \mathrm{mL}$ GO and $81.3 \mu \mathrm{g} / \mathrm{mLQAS}$, or $100 \mu \mathrm{g} / \mathrm{mL}$ GO-QAS. After incubation, diluted cells were spread onto LB plates and left to grow overnight at $37{ }^{\circ} \mathrm{C}$. Colonies were counted, and the numbers were compared with control plates to calculate the cell viability rate.

\section{Antimicrobial property of GO-QAS against multidrug- resistant bacteria}

The antimicrobial property of GO-QAS against MRSA and MDR-AB was determined by the two-fold dilution method [38]. Bacteria $\left(\mathrm{OD} 600_{\mathrm{nm}}=0.5\right)$ were exposed to a two-fold serial dilution of GO-QAS (from 0 to $200 \mu \mathrm{g} / \mathrm{mL}$ ) in $\mathrm{LB}$ broth and incubated at $37{ }^{\circ} \mathrm{C}$ for $24 \mathrm{~h}$. Penicillin and streptomycin were used as the positive control for MRAS and MDR-AB, respectively. After $24 \mathrm{~h}$ of incubation, the optical density at $600 \mathrm{~nm}$ was measured with an enzymelinked immunosorbent assay microplate reader, and bacterial cells were spread onto agar plates after serial dilution for colony counting.

\section{Investigation of the antibacterial mechanisms of GO-QAS} Cell morphology observation with SEM

The morphological changes in bacterial cells after GO, QAS, and GO-QAS treatments were observed with SEM as previously reported [4]. E. coli was chosen as the bacteria for the experiment. Briefly, after incubation with GO, QAS, and GO-QAS dispersions at $200 \mu \mathrm{g} / \mathrm{mL}$ or control (sterile deionized water) for $2 \mathrm{~h}, 100 \mu \mathrm{L}$ of the mixture was diluted to a $1 \mathrm{~mL}$ volume. Then, $20 \mu \mathrm{L}$ of the bacteria-nanocomposite mixture was dropped on the surface of sterile glass coverslips, fixed with $2.5 \%$ glutaraldehyde for $2 \mathrm{~h}$ at room temperature, and washed twice with $0.9 \% \mathrm{NaCl}$ solution, followed by dehydration in a graded ethanol series and drying overnight at room temperature. The glass coverslips were then Au sputtercoated for $60 \mathrm{~s}$ before imaging via SEM (Zeiss Crossbeam 340, Germany) under high-vacuum conditions at an accelerating voltage of $2.0 \mathrm{kV}$.

\section{Reactive oxygen species (ROS) detection}

The oxidation-sensitive fluorescent dye 2', 7'dichlorofluorescin diacetate (DCFH-DA, Sigma-Aldrich, USA) was utilized to detect reactive oxygen species generation in the bacteria suspension according to a previously reported protocol [35]. In brief, $2 \mathrm{~mL}$ of E. coli bacterial suspensions were incubated with $200 \mu \mathrm{L}$ of GO, QAS, and GO-QAS dispersions at $200 \mu \mathrm{g} / \mathrm{mL}$ or the control (deionized water) for $2 \mathrm{~h}$. Then, the cells 
were washed three times with $0.1 \mathrm{M} \mathrm{PBS}(\mathrm{pH} 7.8)$ and resuspended in $2 \mathrm{~mL}$ of PBS solution. Then, $2 \mu \mathrm{L}$ of DCFH-DA $(10 \mathrm{mM})$ was added to make the final concentration of DCFH-DA $10 \mu \mathrm{M}$ in the mixture. Afterwards, the mixture was incubated in the dark for $1 \mathrm{~h}$, centrifuged, and washed to remove the unloaded DCFHDA probe. The fluorescence intensity was measured on an enzyme-linked immunosorbent assay microplate reader (Thermo Varioskan Flash, USA) at an excitation wavelength of $488 \mathrm{~nm}$ and emission wavelength of $525 \mathrm{~nm}$. The intracellular ROS level is expressed as the percentage of the fluorescence intensity of the samples to that of the control.

\section{Measurement of cytoplasmic DNA and RNA efflux}

Bacterial cell membrane integrity was examined by detecting the release of cytoplasmic nucleic acids (DNA and RNA) at $260 \mathrm{~nm}$ absorption according to a previous protocol [39]. Briefly, $2 \mathrm{~mL}$ of E. coli bacterial suspension was incubated with $200 \mu \mathrm{L}$ of GO, QAS, and GOQAS dispersions at $200 \mu \mathrm{g} / \mathrm{mL}$ or the control (deionized water) for $2 \mathrm{~h}$ at $37{ }^{\circ} \mathrm{C}$. The mixture was then immediately filtered with $0.2-\mu \mathrm{m}$ syringe filters to remove bacteria and nanocomposites. The efflux of cytoplasmic nucleic acids from the bacteria into the supernatant was measured with an ND-1000 spectrophotometer (NanoDrop) at $260 \mathrm{~nm}$.

\section{In vitro cytotoxicity and hemolysis assay Cell culture}

A human immortalized keratinocyte $(\mathrm{HaCaT})$ cell line was utilized for cytotoxicity investigation of $\mathrm{GO}$ and GO-QAS. Cells were cultured in Dulbecco's modified Eagle's medium (DMEM) supplemented with $10 \%$ fetal bovine serum (FBS), penicillin $(100 \mathrm{U} / \mathrm{mL})$, and streptomycin $(100 \mu \mathrm{g} / \mathrm{mL})$ in a $5 \% \mathrm{CO}_{2}$ incubator at $37^{\circ} \mathrm{C}$.

\section{Cell viability test}

Cell viability was detected with a Cell Counting Kit-8 (CCK-8) assay based on a previously reported method [35]. In brief, $3 \times 10^{4}$ cells in $150 \mu \mathrm{L}$ of DMEM supplemented with $10 \%$ FBS were seeded into 96-well plates and incubated in a $5 \% \mathrm{CO}_{2}$ incubator at $37^{\circ} \mathrm{C}$ for $24 \mathrm{~h}$. Then, the culture medium was discarded, and $\mathrm{HaCaT}$ cells in the plates were gently rinsed twice with sterile PBS, followed by addition of GO and GO-QAS dispersions at different concentrations or control (deionized water) to the medium and another $24 \mathrm{~h}$ of incubation at $37{ }^{\circ} \mathrm{C}$. After incubation, the culture medium was aspirated, and cells were washed twice with sterile PBS, followed by addition of $10 \mu \mathrm{LL}$ of CCK-8 reagent (Dojindo, Kyushu, Japan) and $100 \mu \mathrm{L}$ of fresh DMEM. After $4 \mathrm{~h}$ of further incubation at $37{ }^{\circ} \mathrm{C}$, the sample absorbance was quantitated at $450 \mathrm{~nm}$ using an enzyme-linked immunosorbent assay microplate reader (Thermo Varioskan Flash, USA).

\section{Flow cytometry apoptosis assay}

To further investigate the cytotoxicity of GO-QAS, an Annexin V-FITC apoptosis detection kit (C1062, Beyotime, China) was used to detect the ratio of apoptotic and necrotic cells as previously reported [40,41]. Briefly, after incubation with GO, GO-QAS, or control (deionized water) for $24 \mathrm{~h}, \mathrm{HaCaT}$ cells were collected, washed with cold PBS solution, and resuspended in $195 \mu \mathrm{L}$ of binding buffer, followed by successive addition of $5 \mu \mathrm{L}$ of Annexin V-FITC and $10 \mu \mathrm{L}$ of PI. Then, the mixture was incubated for $15 \mathrm{~min}$ at room temperature in the dark and analyzed with a fluorescence-activated cell sorting (FACS) sorter (Attune acoustic focusing cytometer). The Annexin V-FITC ${ }^{+}$and $\mathrm{PI}^{-}$quadrant represented the apoptotic cells, while the Annexin V-FITC ${ }^{+}$and $\mathrm{PI}^{+}$quadrant represented the necrotic cells.

\section{In vitro hemolysis assay}

The hemolysis assay was carried out based on a previously reported method [42]. A fresh human blood sample was collected from a healthy volunteer in the Southwest Hospital with the donor's consent. Erythrocytes were collected by centrifugation at $1500 \mathrm{rpm}$ for $15 \mathrm{~min}$ and washed three times with saline. Then, $1 \mathrm{~mL}$ of the centrifuged erythrocytes was mixed with $3.67 \mathrm{~mL}$ of saline. Afterwards, $100 \mu \mathrm{L}$ of diluted erythrocyte dispersion was added to $1 \mathrm{~mL}$ of GO and GO-QAS dispersions in saline at different concentrations. Saline and deionized water served as the negative and positive control. The mixed dispersions were incubated at $37^{\circ} \mathrm{C}$ for $3 \mathrm{~h}$. The hemolysis ratio was evaluated by measuring the supernatant at $540 \mathrm{~nm}$ absorbance with an enzymelinked immunosorbent assay microplate reader (Thermo Varioskan Flash, USA) after centrifugation at $12000 \mathrm{rpm}$ for $15 \mathrm{~min}$. The hemolysis ratio was calculated based on the following formula:

$$
\text { Hemolysis ratio } \%=\left(A_{S}-A_{N}\right) /\left(A_{P}-A_{N}\right) \times 100 \%
$$

where $A_{S}$ represented the absorbance of the corresponding nanocomposite, $A_{N}$ was the absorbance of the negative control, and $A_{P}$ represented the absorbance of the positive control.

\section{In vivo biosafety evaluation}

To investigate the biocompatibility of GO-QAS in vivo, mice were intravenously administered $20 \mu \mathrm{L}$ of sterile PBS buffer (10 mM, pH 7.4) or GO and GO-QAS dispersions at $100 \mu \mathrm{g} / \mathrm{mL}$ through the tail vein [43]. Seven days post administration, the mice were sacrificed and organs (including the liver, kidney, spleen, and heart) were harvested. Then, the organs were fixed with 
4\% paraformaldehyde, embedded in paraffin, sectioned at a thickness of $5 \mu \mathrm{m}$, and stained with hematoxylin and eosin (H\&E).

\section{In vivo effect of GO-QAS on wound infection In vivo antimicrobial evaluation and wound healing}

To evaluate the antimicrobial effect of GO-QAS in vivo, a murine-infected full-thickness skin defect wound model was constructed [44]. Briefly, BALB/c mice were intraperitoneally anesthetized with $1 \%$ pentobarbital. The dorsal fur was shaved, and the skin was cleaned with $75 \%$ alcohol. On each side of the back, one 6-mmdiameter full-thickness wound was created with a punch. A 6-mm-diameter sterile round marker was placed beside each wound to represent the initial wound area and the wounds were photographed immediately using a digital camera. Twenty mice were enrolled in the study and randomly divided into blank, control, GO and GOQAS groups, with five mice in each group. GO, GOQAS and control groups were inoculated with a $5 \mu \mathrm{L}$ aliquot of an $S$. aureus and E. coli mixed suspension (at 0.5 McFarland standard), and each wound was treated with $5 \mu \mathrm{L}$ of GO or GO-QAS dispersions at $100 \mu \mathrm{g} / \mathrm{mL}$ (selected based on the cytotoxicity results) or deionized water (control group), respectively. Blank group without bacterial inoculation was used as the negative control. Each wound was then covered with a sterile gauze. Afterwards, a piece of biological membrane (NPWT-1, Negative Pressure Wound Therapy Kit, China) was pasted onto the surface of the gauze. Mouse wounds without infection were used as the negative control. At days 3,5 , and 7 post-infection, the wounds were photographed, and the number of bacteria on the wound was quantified using the plate count method. Wound areas were measured using IPP 6.0 software. The wound healing rate was calculated based on the following formula:

Wound healing rate $\%=(I-R) / I \times 100 \%$

where $I$ represented the initial wound area and $R$ represented the wound area that remained on the determined day post-infection [45].

\section{Histological analysis of wound tissues}

For histological analysis, mice were sacrificed on day 3 or 7 post-surgery. The skin wound specimens were harvested, fixed with $4 \%$ paraformaldehyde, embedded in paraffin, cut at a thickness of $5 \mu \mathrm{m}$, and then stained with H\&E. The length of the neo-epithelium and the granulation tissue thickness were measured using ImageJ software. The length of the neo-epithelium is defined as the distance between the wound margin and the advancing edge of the epidermis [45]. All software measurements were performed by two independent researchers.

\section{Results}

Synthesis and characterization of antibacterial GO-QAS nanosheets

The synthetic route for antibacterial GO-QAS nanosheets is shown in Scheme 1. The quaternary ammonium polymers containing GO nanosheets were fabricated via four reaction steps. The quaternary ammonium monomer was prepared by quaternization of the hydrophobic compound 1-bromohexane with an acrylate monomer containing the tertiary amine 2-(dimethylamino) ethyl acrylate (DMAEA). The quaternary ammonium monomer AEDMHA was sequentially polymerized via the reversible addition-fragmentation chain transfer (RAFT) polymerization technique, which is versatile and has a high tolerance to functional groups. The monomers were initiated with a carboxylic acid-containing chain transfer agent (RAFT-COOH) to polymerize the carboxylic group end-capped QAS polymer chains. Their ${ }^{1} \mathrm{H}$ NMR spectra are presented in Fig. 1a, b. Compared with the spectrum of monomers, the peaks at 5.90 6.40 ppm assigned to protons on $\mathrm{C}=\mathrm{C}$ double bonds disappeared after polymerization, indicating successful polymerization. The broadened peaks of quaternary ammonium pendants also confirmed the formation of a polymeric configuration, and the broad peak at $2.55 \mathrm{ppm}$ that appeared was attributed to the newly formed $-\mathrm{CH}-\mathrm{CH}_{2}$ - single bonds on the polymer backbone. The polymerization degree could be estimated by comparing the peak intensity of the three residual peaks at 5.90 6.40 ppm from the three protons on acrylates with the peak at $0.9 \mathrm{ppm}$ attributed to the methyl groups on the pendant ends, and the number-average molecular weight $(\mathrm{Mn})$ of the polymers was calculated as $7400 \mathrm{Da}$, with a conversion rate of $\sim 93 \%$. To conjugate the carboxylic acid end-capped polymers, the GO nanosheet surface was decorated with amine groups via silanization with (3-aminopropyl)trimethoxysilane (APTMS). After silanization, the $\mathrm{GO}-\mathrm{NH}_{2}$ suspension became aggregated and viscous, which may be attributed to ionic interactions between the introduced amines and carboxylic acids on the GO nanosheets. Based on the reaction yield, at least 0 . 89 mol APTMS/100 g GO (or 133 g APTMS/100 g GO) should have been grafted onto nanosheets. Finally, the carboxylic acid-capped quaternary ammonium polymers were covalently bonded to $\mathrm{GO}-\mathrm{NH}_{2}$ nanosheets via an amidation reaction with EDC/NHS catalysis, and four groups of GOQAS nanocomposites with different QAS graft ratios were prepared by varying the feeding ratios of the $\mathrm{GO}-\mathrm{NH}_{2}$ and QAS polymers. After removal of the unconjugated polymers via dialysis and lyophilization, the graft ratios of QAS in GO-QAS nanosheets were estimated by calculating the product yields, and the loading ratios of QAS changed from 50 to 86.3 wt\% of the overall solid content (see Additional file 1: Table S1). The obtained GO-QAS nanocomposites showed good dispersion stability in water. 


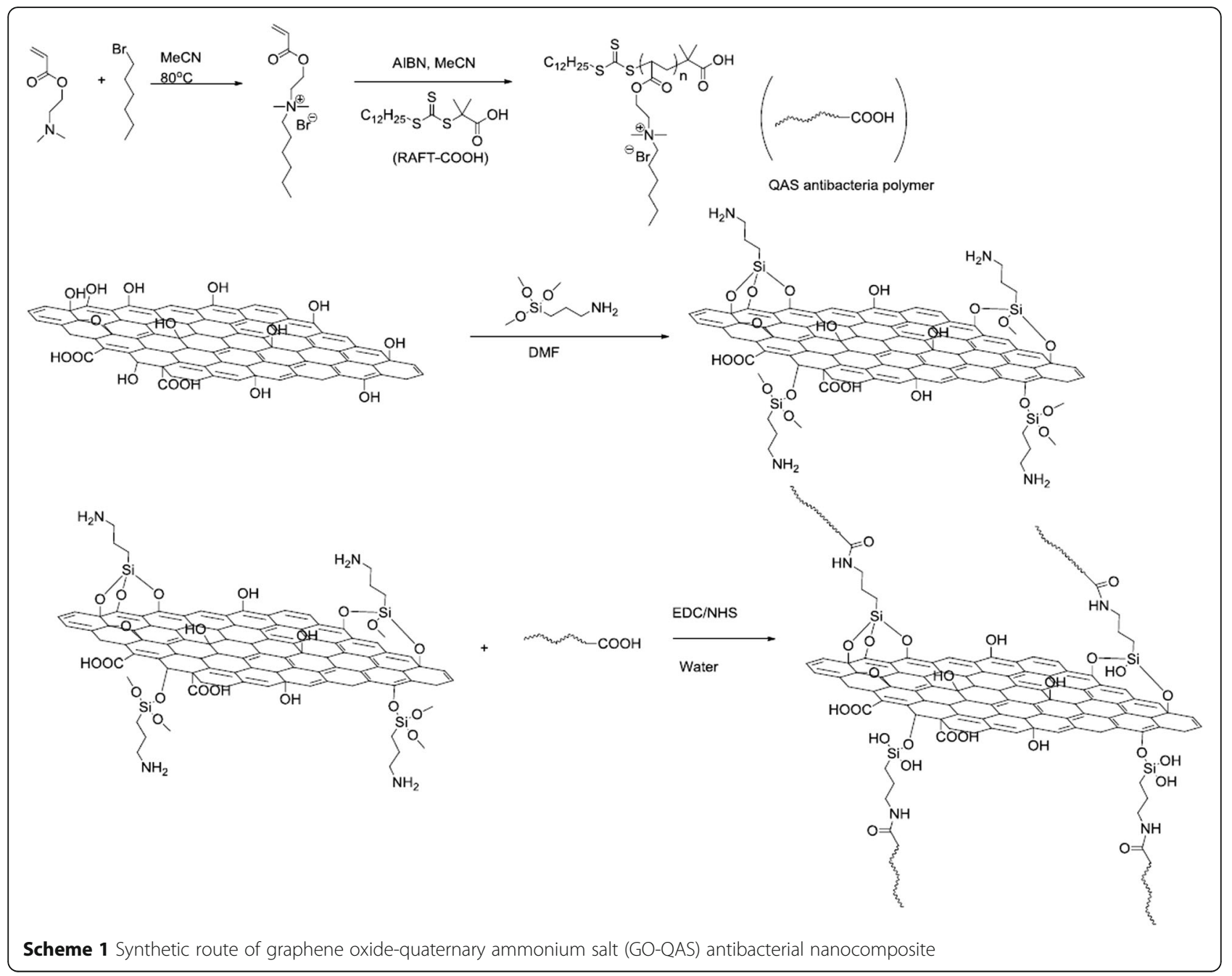

According to the FTIR-ATR spectra in Fig. 1c, the broad peak at $3200 \sim 3700 \mathrm{~cm}^{-1}$ was from the hydroxyl groups on GO, while the broad peak at $2500 \sim 3200 \mathrm{~cm}^{-1}$ was attributed to $\mathrm{O}-\mathrm{H}$ stretching of carboxylic acid groups on the GO surface. After silanization, the sharp peak that appeared at $2940 \mathrm{~cm}^{-1}$ was from alkyl -CHstretching in aminopropyl groups, while the strong peak at $1050 \mathrm{~cm}^{-1}$ is likely due to $\mathrm{Si}-\mathrm{O}$ bond stretching, which confirmed successful silanization of APTMS on GO. Based on the spectrum of GO-QAS, the strong peaks at 2970 and $2940 \mathrm{~cm}^{-1}$ were due to $\mathrm{C}-\mathrm{H}$ stretching in the- $\mathrm{CH}_{3}$ and $-\mathrm{CH}_{2}$ - groups of the quaternary ammonium polymers. Moreover, the sharp strong peak at $1730 \mathrm{~cm}^{-1}$ was assigned to $\mathrm{C}=\mathrm{O}$ stretching of esters in polyacrylate, while another strong peak at $1170 \mathrm{~cm}^{-1}$ was from $\mathrm{C}-\mathrm{O}$ stretching of esters, which demonstrated the conjugation of polymer chains onto $\mathrm{GO}$ nanosheets. The high peak intensity of the polymer functional groups suggested a high polymeric content in the GOQAS nanocomposite. To further confirm the various QAS graft ratios, four GO-QAS groups and pure QAS polymer were characterized by FTIR-ATR. The sharp peak at $1730 \mathrm{~cm}^{-1}$ was only attributed to ester groups in QAS polymers, while the peak at $1050 \mathrm{~cm}^{-1}$ was from the overlap of the strong peak of $\mathrm{Si}-\mathrm{O}$ on $\mathrm{GO}-\mathrm{NH}_{2}$ nanosheets and the weak peak of C-N bonds on both $\mathrm{GO}-\mathrm{NH}_{2}$ and QAS polymers, and therefore, the graft ratios of QAS onto GO- $\mathrm{NH}_{2}$ could be evaluated by comparing the relative peak intensities of these two regions. As shown in Fig. 1d, the peak intensity at $1730 \mathrm{~cm}^{-1}$ was normalized for all samples, and the absorption peak intensity at $1050 \mathrm{~cm}^{-1}$ became weaker from GO-QAS-1 to GOQAS-4 sequentially, showing that GO-QAS-1 has the lowest QAS graft ratio and GO-QAS-4 has the highest graft ratio among the nanocomposites.

The surface morphologies of purchased $\mathrm{GO}$ and synthesized GO-QAS were explored by SEM and TEM. According to the SEM images in Fig. 2a-d, it was evident that GO possessed a number of closely stacked sheets with significantly wrinkled surfaces. In contrast, it seems that GO-QAS had relatively less closely stacked 


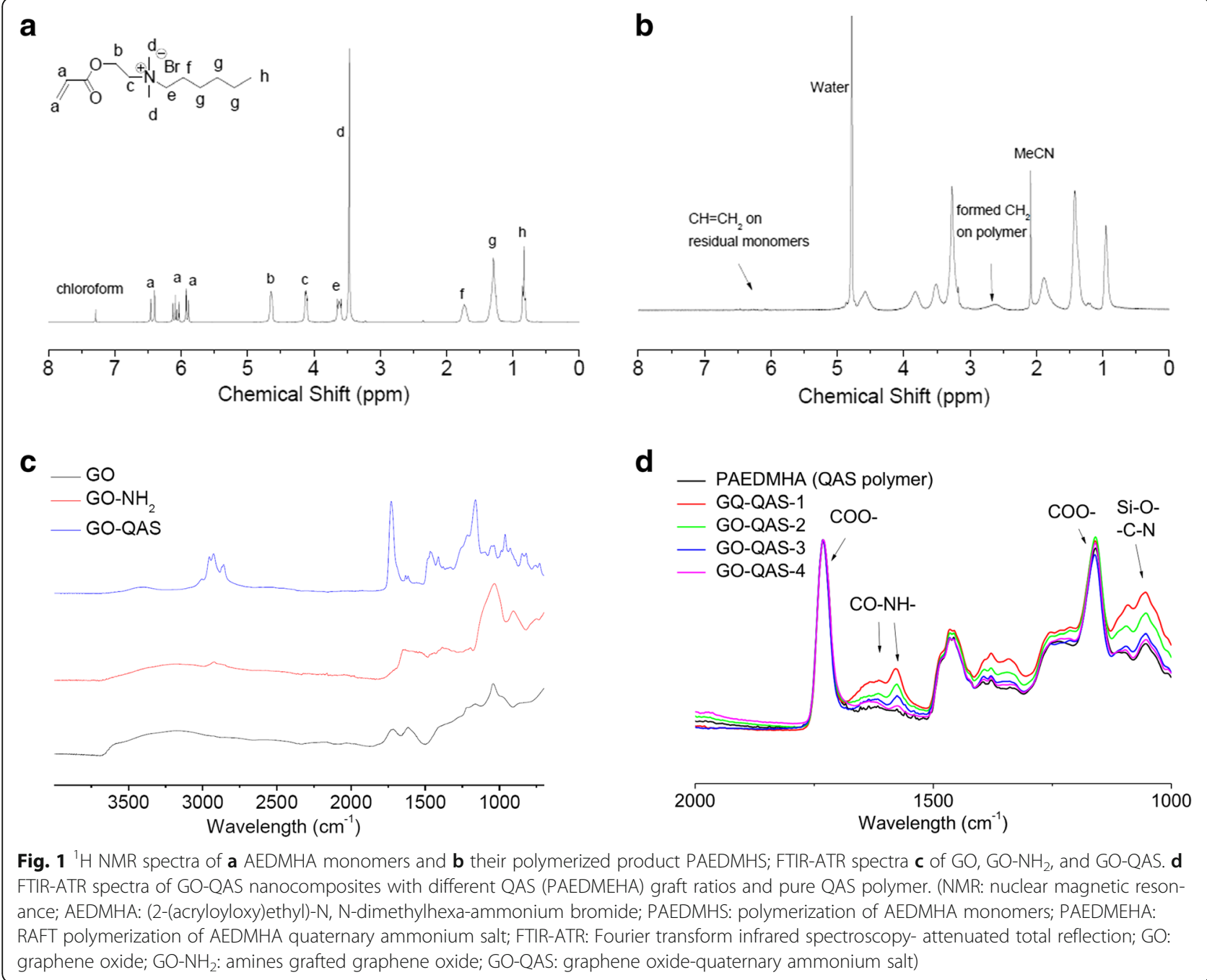

sheets and were better distributed than the GO nanosheets, which was attributed to the presence of QAS functioning as a cationic surfactant to facilitate dispersion, as shown in Figure S4 (see Additional file 1). Further and more distinct morphology confirmation was obtained from the TEM images in Fig. 2e-f. We found that both GO and GO-QAS exhibited a sheet-like morphology with high transparency. In addition, there were some wrinkles and folded regions in both the GO and GO-QAS nanosheets.

Based on the AFM height profiles shown in Fig. 3, both GO and GO-QAS were composed of monodispersed layers. The bare GO (Fig. 3b) sample exhibited a height of $0.8 \mathrm{~nm}$, which was a characteristic of fully exfoliated single-layer GO [33]. However, GO-QAS (Fig. 3d) presented an approximately $1 \mathrm{~nm}$ height thickness, with a lateral size similar to that of GO. The increase in the height of GO-QAS was caused by the coverage of QAS on the basal plane of GO, which also indirectly indicated the formation of the GO-QAS nanocomposite.
The particle size distribution of GO and GO-QAS was characterized by DLS. According to the DLS results shown in Fig. 4a, we found that both GO and GO-QAS exhibited a wide size distribution, with the majority dispersed within a narrow range. The average particle size was 223 and $255 \mathrm{~nm}$ for GO and GO-QAS, respectively. The surface charge of the nanoparticles was characterized by zeta potential using DLS. As shown in Fig. 4b, the zeta potential of GO was -36 . $03 \mathrm{mV}$, while the zeta potential of GO-QAS was 42 . $01 \mathrm{mV}$. The observed surface charge difference was due to the presence of positively charged QAS on GO nanosheets, indicating a successful synthesis of the GO-QAS nanocomposite.

The thermal stability of pre-dried $\mathrm{GO}, \mathrm{GO}-\mathrm{NH}_{2}$, and GO-QAS (GO-QAS-3) samples was characterized by thermogravimetric analysis, as presented in Fig. 4c. When the temperature was below $140{ }^{\circ} \mathrm{C}$, the mass losses were $15.8,7.8$, and $1.4 \%$ for $\mathrm{GO}, \mathrm{GO}-\mathrm{NH}_{2}$, and GO-QAS (GO-QAS-3), respectively, due to water loss. 

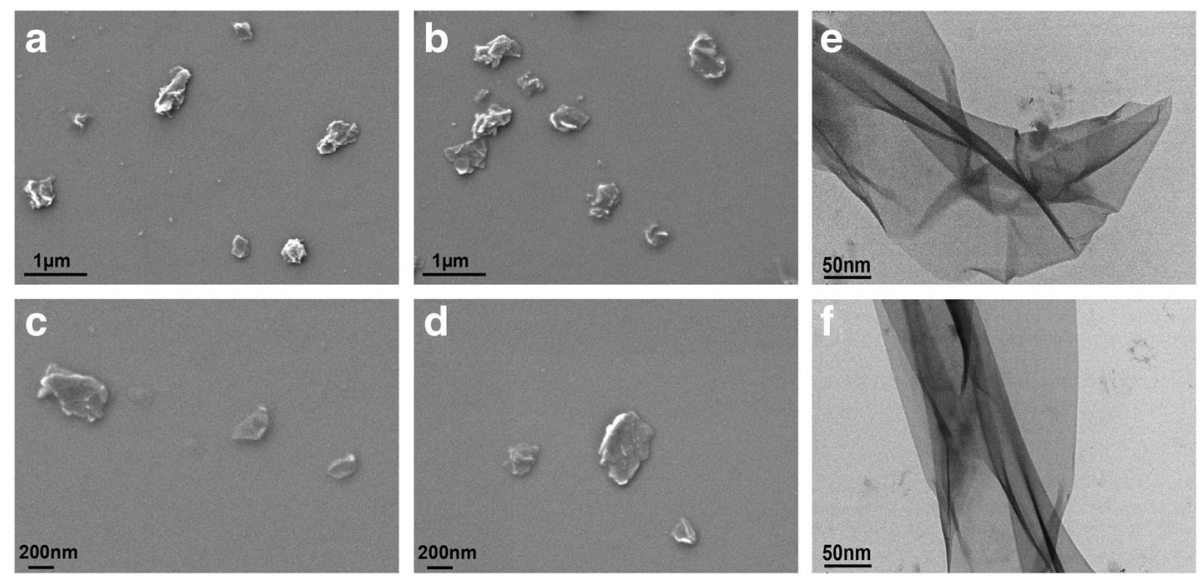

Fig. 2 Scanning electron microscopy images of graphene oxide (GO) (a, c) and graphene oxide-quaternary ammonium salt (GO-QAS) (b, d). Transmission electron microscopy images of $\mathbf{e} \mathrm{GO}$ and $\mathbf{f} \mathrm{GO}-\mathrm{QAS}$

Interestingly, the water loss seemed to mainly be attributed to the GO nanosheet binding interaction and was proportional to the $\mathrm{GO}$ weight fractions in the nanocomposites. By calculation, the GO-QAS nanocomposites contained $8.9 \mathrm{wt} \% \mathrm{GO}, 9.2 \mathrm{wt} \%$ APTMS, and 81 . $9 \mathrm{wt} \%$ QAS, which was in line with the weight fractions based on reaction yields. At $150 \sim 200{ }^{\circ} \mathrm{C}$, graphene oxide began to degrade due to deoxygenation of the carboxylic acid and hydroxyl groups. GO and GO- $\mathrm{NH}_{2}$ had $\sim 20$ and $\sim 10 \%$ mass loss, respectively, according to their GO content. GO-QAS had 9\% mass loss not only because of deoxygenation but also due to Hofmann degradation of quaternary ammonium salts, and therefore, GO-QAS could maintain thermal stability below $150{ }^{\circ} \mathrm{C}$.

\section{In vitro antibacterial activity of GO-QAS nanosheets Optimization of the antibacterial activity of GO-QAS by modulating the QAS graft ratio}

To optimize the QAS graft ratio so that GO-QAS could exhibit the highest possible antibacterial activity, we
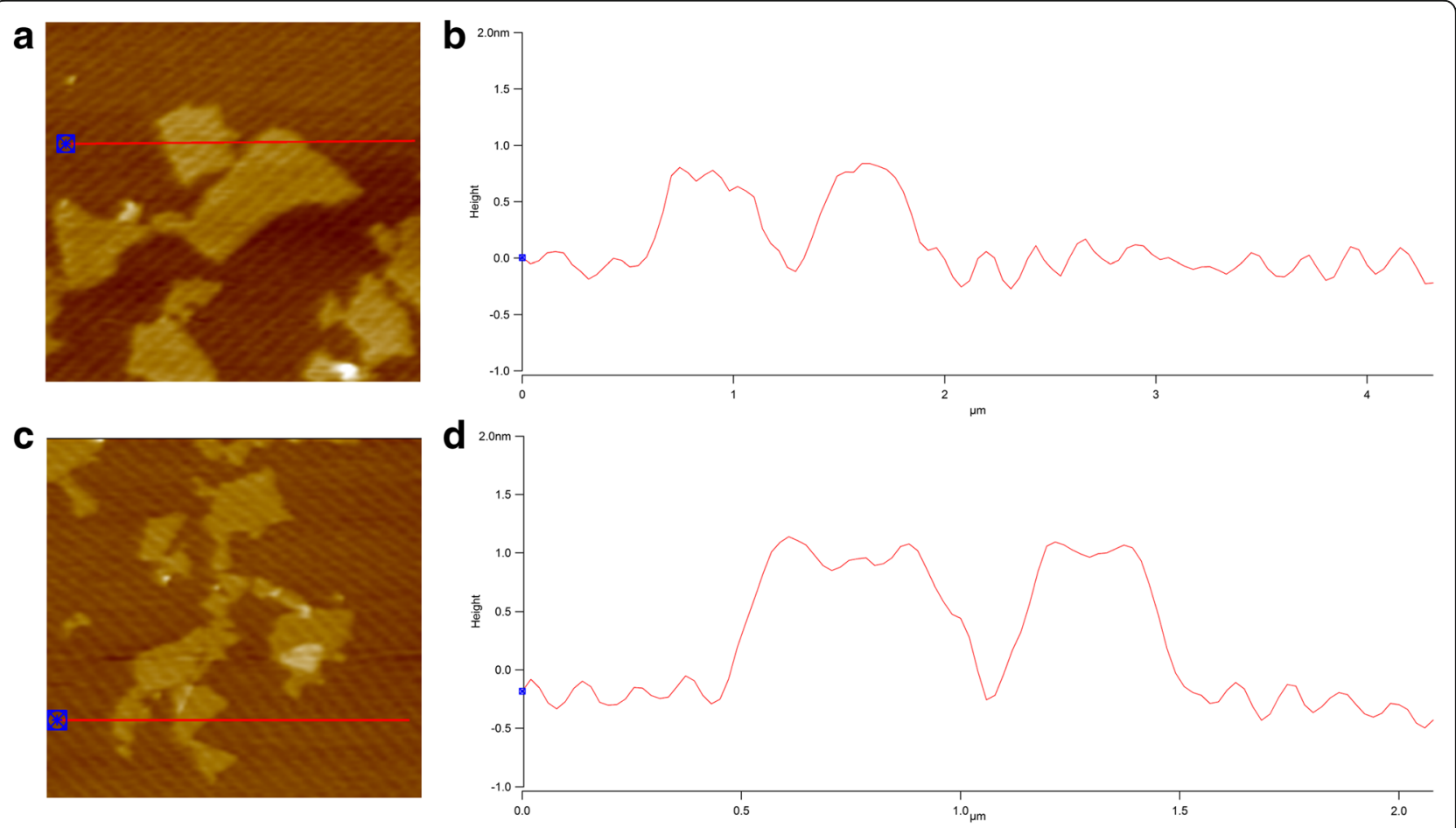

Fig. 3 Atomic force microscopy results of graphene oxide $(\mathbf{a}, \mathbf{b})$ and graphene oxide-quaternary ammonium salt $(\mathbf{c}, \mathbf{d})$ 

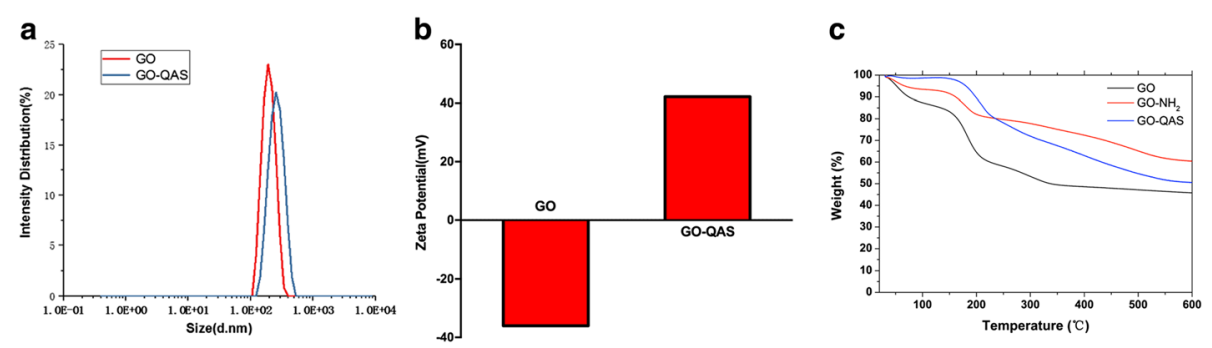

Fig. 4 a Dynamic light scattering results of GO and GO-QAS. b Zeta potential results of GO and GO-QAS. c Thermogravimetric analysis results of GO, GO-NH 2 , and GO-QAS. (DLS: dynamic light scattering; TGA: thermogravimetric analysis; GO: graphene oxide; GO- $\mathrm{NH}_{2}$ : amines grafted graphene oxide; GO-QAS: graphene oxide-quaternary ammonium salt)

tailored the overall graft ratios of QAS polymers on GO nanosheets to evaluate the antibacterial capacity of four GO-QAS (GO-QAS 1, 2, 3, and 4) nanocomposites at $50 \mu \mathrm{g} / \mathrm{mL}$ with different quaternary ammonium salt levels of $50,69.7,81.3$, and $86.3 \mathrm{wt} \%$, respectively (see Additional file 1: Table S1). As shown in Fig. $5 a-b$, an increased QAS graft ratio enhanced the antibacterial activity of GO-QAS when the QAS mass fraction in GO-QAS was up to $81.3 \%$ (GO-QAS-3), but a continuously increased QAS graft ratio led to a drop in antibacterial performance. Among the four GO-QAS nanosheet groups, GO-QAS-3 showed the highest

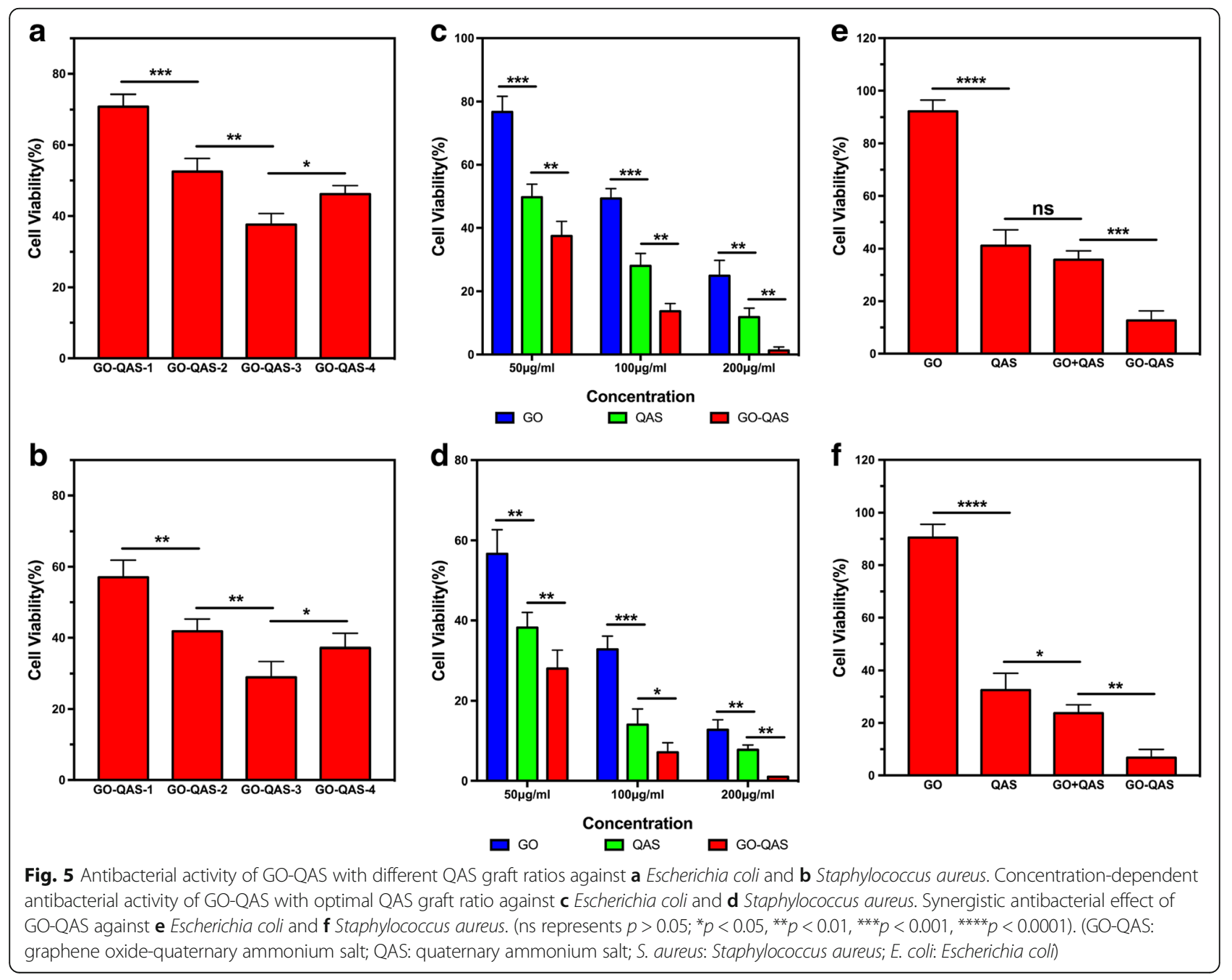


antibacterial activity against both $E$. coli and $S$. aureus. Therefore, GO-QAS-3 (the optimized GOQAS) was utilized in the following experiments.

\section{Antibacterial activity of optimized GO-QAS nanosheets at different concentrations}

Agar diffusion test The antibacterial activity of optimized GO-QAS nanosheets was qualitatively analyzed and compared with $\mathrm{GO}$ by observing the transparent halo around the well (see Additional file1: Figure S1). It was found that GO-QAS at a concentration higher than $10 \mu \mathrm{g} / \mathrm{mL}$ had obviously visible bactericidal activity against both gram-positive and gram-negative bacteria. In addition, the inhibition zone for gram-positive bacteria was much clearer and larger than that for gramnegative bacteria. Based on the agar diffusion test results, we chose GO-QAS dispersion concentrations of 50,100 , and $200 \mu \mathrm{g} / \mathrm{mL}$ to carry out the following experiments.

Plate count method The bactericidal effect of GO, QAS, and GO-QAS dispersions on gram-positive and gram-negative bacteria was quantitatively evaluated by counting the number of colony forming units (CFU) on an agar plate (Fig. $5 \mathrm{c}-\mathrm{d}$ ). The results showed that GO, QAS, and GO-QAS could significantly eradicate both gram-positive and gram-negative bacteria. The cell viability decreased gradually as the concentration increased, which was demonstrated by the sequentially decreasing number of CFU on the LB plates (see Additional file1: Figure S3). GO-QAS at $200 \mu \mathrm{g} / \mathrm{mL}$ almost completely killed both gram-positive and gram-negative bacteria, while GO and QAS at the highest concentration caused approximately $87 \%$ and $92 \%$ cell death for S. aureus and $75 \%$ and $88 \%$ cell death for E. coli, respectively.

Bacterial live/dead viability assay To demonstrate the reliability of the GO, QAS, and GO-QAS antibacterial activity results obtained using the plate count method, a live/dead viability assay was performed to further evaluate the antimicrobial activity of GO, QAS, and GO-QAS at $200 \mu \mathrm{g} / \mathrm{mL}$. Typically, SYTO 9 dye (green) stains both live and dead cells, while PI (red) only stains dead cells with compromised membranes. The cell mortality ratio $\%$ is expressed as the number of dead cells (red)/the number of total cells (green) $\times 100 \%$. As shown in Fig. 6, bacteria in the control group were all stained green, while some bacteria incubated with GO, QAS, and GOQAS were stained red. The results showed that GOQAS at $200 \mu \mathrm{g} / \mathrm{mL}$ could kill $95.5 \%$ of gram-positive and 95\% of gram-negative bacteria, while GO and QAS could kill $80 \%$ and $90 \%$ of gram-positive and 73 and $85 \%$ of gram-negative bacteria, respectively.

\section{Synergistic antibacterial effect of GO-QAS}

Based on the results shown in Table S1 (see Additional file 1), the GO and QAS content in optimized GO-QAS (GO-QAS-3) was $8 \%$ and $81.3 \%$, and thus, $100 \mu \mathrm{g} / \mathrm{mL}$ of GO-QAS suspension contained $8 \mu \mathrm{g} / \mathrm{mL} \mathrm{GO}$ and 81 . $3 \mu \mathrm{g} / \mathrm{mL}$ QAS. To further demonstrate that the significantly enhanced antibacterial activity of GO-QAS nanocomposite was attributed to a synergistic antibacterial effect of GO and QAS, instead of merely an additive effect of the two constituents mixed together, bacterial cells were treated with $8 \mu \mathrm{g} / \mathrm{mL}$ GO, $81.3 \mu \mathrm{g} / \mathrm{mL}$ QAS, a mixture of $8 \mu \mathrm{g} / \mathrm{mL}$ GO and $81.3 \mu \mathrm{g} / \mathrm{mL}$ QAS, or $100 \mu \mathrm{g} / \mathrm{mL}$ of GO-QAS. As shown in Fig. $5 \mathrm{e}-\mathrm{f}$, the losses in $E$. coli cell viability were only $7.8 \%, 58.8 \%$, and $61.8 \%$ with GO, QAS, and the mixture of GO and QAS, respectively. For $S$. aureus, the results were 9.5\%, 67.5\%, and $74.6 \%$, respectively. By comparison, the losses in $E$. coli and $S$. aureus viability were $87.4 \%$ and $93.2 \%$ with GO-QAS, respectively. Therefore, the combined antibacterial activity of GO-QAS was not simply the additive effect of the two constituents, but rather attributed to a synergistic antibacterial effect.

\section{Antibacterial mechanisms of GO-QAS nanosheets}

Cell morphology observation via SEM To investigate the bacterial morphology changes after GO-QAS treatment, SEM was applied to observe $E$. coli morphology after exposure to nanosheets for $2 \mathrm{~h}$. According to the SEM results shown in Fig. 7, E. coli without nanosheet treatment showed a typical rod-shaped morphology, with intact and smooth cell walls. However, after being treated with GO, QAS, and GO-QAS, the majority of bacteria lost their cellular integrity, and bacteria length tended to shorten, with the bacterial surface becoming rough and wrinkled. Interestingly, we found that E. coli were wrapped up or stabbed by nanosheets and cell walls collapsed after GO and GO-QAS treatments (bacteria stained green and blue in Fig. 7). Such results were consistent with previous reports on the antibacterial mechanism of GO [33], indicating that the wrapping/trapping and incision mechanisms were shared by both GO and GO-QAS. Notably, the physical cleavage force was so strong that we observed many cells split into two halves (bacteria stained yellow in Fig. 7), which to the best of our knowledge has never been reported in previous literature. Additionally, there were some pores formed on the cell membrane after GO-QAS treatment (bacteria stained red in Fig. 7), which was similar to the morphology of E. coli after QAS treatment, but quite different from that after GO treatment.

Measurement of cytoplasmic DNA and RNA efflux If the bacteria membrane was disrupted, the cytoplasmic 


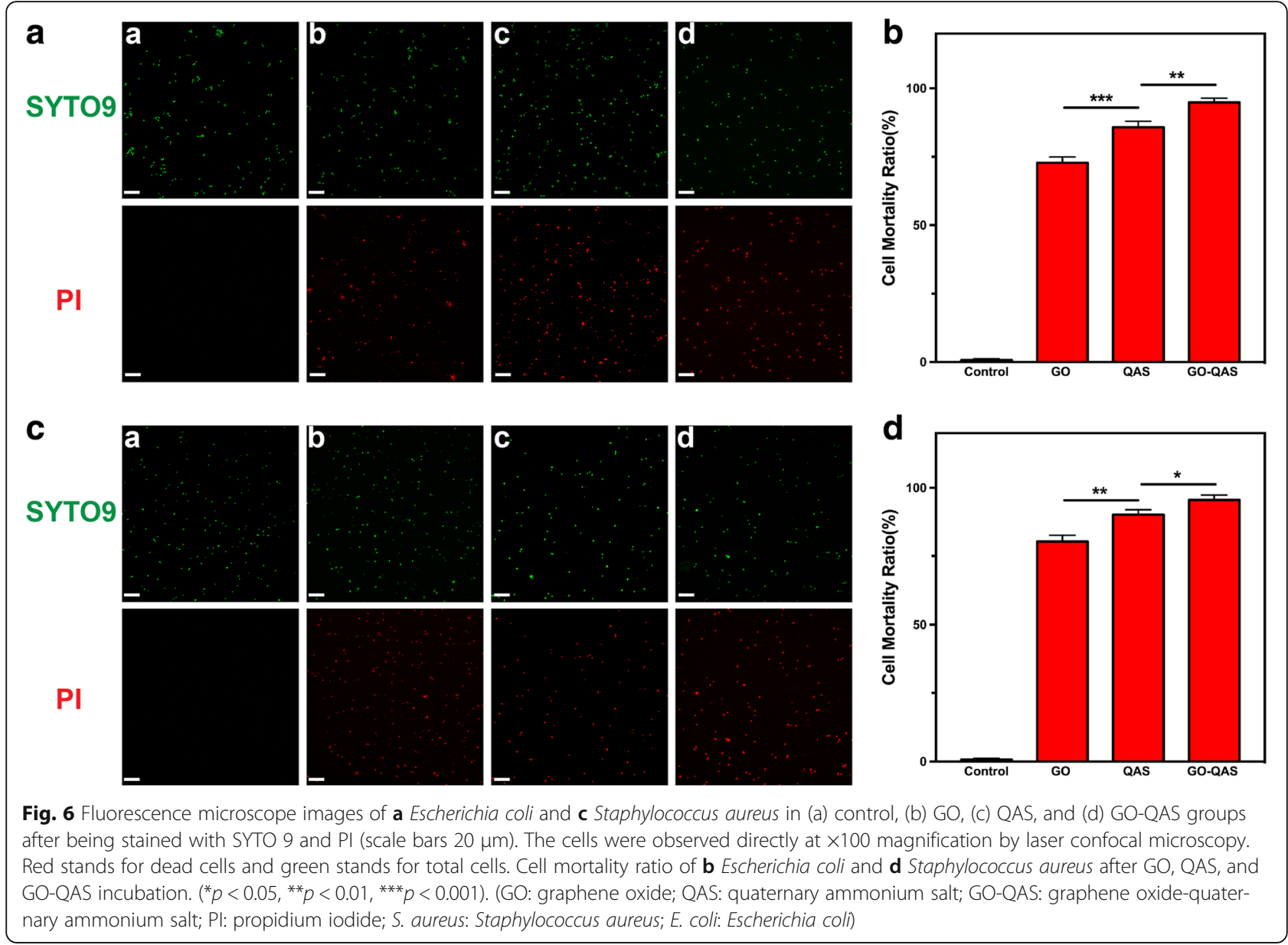

contents, such as nucleic acids (DNA and RNA), would be released from the damaged bacteria and could be monitored in the supernatant via the $260 \mathrm{~nm}$ absorption. After bacteria were incubated with GO, QAS, and GO-QAS, the nucleic acid concentrations in the supernatant were measured (Fig. 8a). Compared with the control group, the nucleic acid concentrations were significantly higher after GO, QAS, and GO-QAS treatments. Such results further confirmed the bacteria membrane disruption observed with SEM. The efflux concentrations of cytoplasmic nucleic acids were $2.25,4.7$, and $7.1 \mathrm{ng} / \mu \mathrm{L}$ with GO, QAS, and GO-QAS, respectively. The nucleic acid concentration in the GO-QAS group was significantly higher than those in the GO and QAS groups. These results indicated that the membrane disruption ability of GO-QAS was stronger than that of GO and QAS, likely due to the synergistic effect of the grafted QAS and GO nanosheets.

Reactive oxygen species detection To further investigate whether the antimicrobial mechanism of GOQAS involved oxidative stress induction, the ROS content in bacteria after nanosheet treatment was measured using DCFH-DA. Briefly, DCFH-DA is a non-fluorescent chemical compound and can freely penetrate the cell membrane. After entering the cell, it is hydrolyzed to DCFH by intracellular esterase and becomes unable to permeate the cell membrane. Intracellular ROS oxidize the non-fluorescent DCFH to fluorescent DCF, which can be measured at a 488$\mathrm{nm}$ excitation wavelength and a 525-nm emission wavelength. Thus, the intracellular ROS level is indicated by the increase in fluorescence intensity. As shown in Fig. 8b, the ROS level was approximately 1 . 3-fold, 1.5-fold, and 1.8-fold higher than that of the control after GO, QAS, and GO-QAS treatments, respectively.

\section{Antimicrobial property of GO-QAS against multidrug-resistant bacteria}

The antimicrobial property of GO-QAS against MRSA and MDR-AB is shown in Additional file 1: Figure S2. The results illustrate that GO-QAS can significantly inhibit multidrug-resistant bacteria growth and eradicate both MRSA and MDR-AB. Compared with conventional antibiotics (penicillin and streptomycin), GO-QAS possessed more powerful antimicrobial activity against 



Fig. 7 Scanning electron microscopy images of Escherichia coli cells treated a without nanocomposite, b with graphene oxide (GO) suspensions, c with quaternary ammonium salt (QAS) suspensions, and $\mathbf{d}$ with GO-QAS suspensions, respectively. Bacteria stained in green color represent nanosheets wrapping/trapping bacteria. Bacteria stained in blue color indicate nanosheets inserting into bacteria membrane. Bacteria stained in red color denote bacteria membrane perforated by nanocomposite with pores formed on the cell membrane. Bacteria stained in yellow color indicate bacteria split into two halves by nanosheets

multidrug-resistant bacteria. In addition, we found that MRSA was more sensitive to GO-QAS than MDR-AB.

\section{In vitro cytotoxicity and hemocompatibility study Cell viability test}

The cytotoxicity of nanosheets to mammalian cells was evaluated using CCK- 8 assays to measure the viability of $\mathrm{HaCaT}$ cells exposed to different concentrations of samples for $24 \mathrm{~h}$ (Fig. 9a). The results revealed that $\mathrm{GO}$ exhibited no obvious cytotoxicity to $\mathrm{HaCaT}$ cells even at the high concentration of $200 \mu \mathrm{g} / \mathrm{mL}$, and GO-QAS at concentrations lower than $200 \mu \mathrm{g} / \mathrm{mL}$ showed no obvious cytotoxicity. However, GO-QAS at $200 \mu \mathrm{g} / \mathrm{mL}$ exhibited slight cytotoxicity towards $\mathrm{HaCaT}$ cells, evidenced by the cell viability decrease to approximately $90 \%$ after $24 \mathrm{~h}$ of incubation, which indicated that the cytotoxicity of GO-QAS was mainly caused by the grafted QAS group at high concentrations.

\section{Flow cytometry apoptosis assay}

To further determine the cytotoxicity of GO-QAS towards mammalian cells, we employed an Annexin VFITC apoptosis detection kit to detect the ratio of apoptotic and necrotic cells after incubation with different concentrations of nanocomposites (Fig. 9b-d). The flow cytometry apoptosis assay results showed that there was no significant difference in the percentage of necrotic cells between the GO and GO-QAS groups at concentrations lower than $200 \mu \mathrm{g} / \mathrm{mL}$. However, GO-QAS at $200 \mu \mathrm{g} / \mathrm{mL}$ induced a significantly higher ratio of necrotic cells (Fig. 9c), which corroborated the results obtained with the CCK- 8 assays and inverted phase contrast microscopy. In addition, it was intriguing to find that there was no significant difference in the ratio of apoptotic cells (Fig. 9d) induced by GO and GO-QAS.

\section{Hemolysis assay}

As shown in Fig. 9e, the hemolysis induction rates of GO and GO-QAS nanosheets at different concentrations 

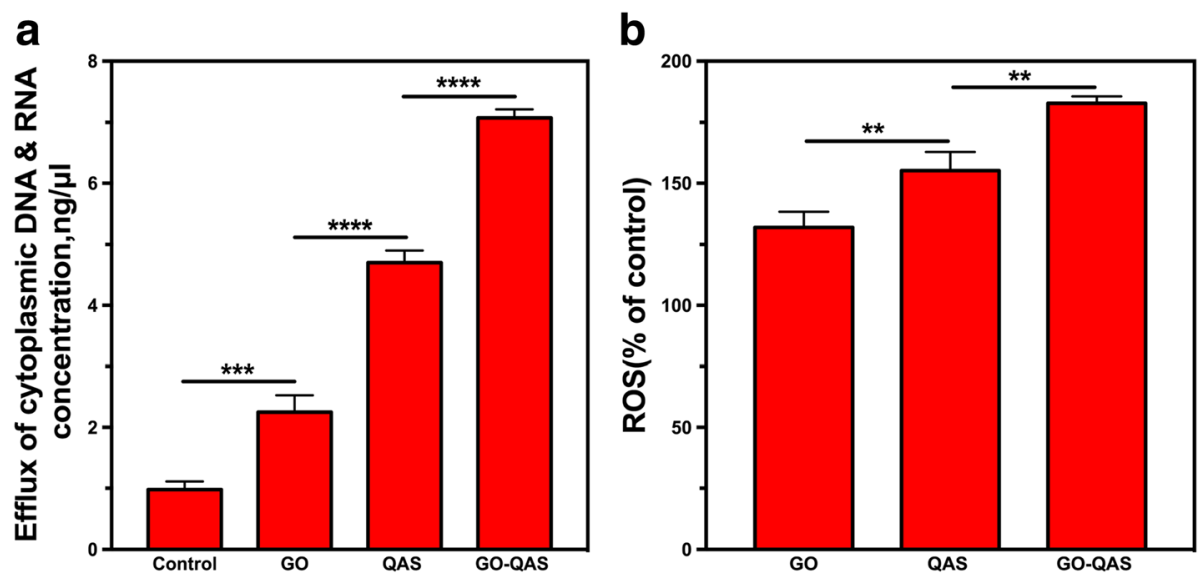

Fig. 8 a The absorbance of efflux of cytoplasmic materials (DNA and RNA) at $260 \mathrm{~nm}$ after bacteria being incubated with GO, QAS, and GO-QAS at $200 \mu \mathrm{g} / \mathrm{mL}$, respectively. $\mathbf{b}$ ROS generation after the bacteria suspensions were incubated with GO, QAS, and GO-QAS dispersions at $200 \mu \mathrm{g} / \mathrm{mL}$ concentration. $\left({ }^{* *} p<0.01,{ }^{* * *} p<0.001,{ }^{* * *} p<0.0001\right)$. (GO: graphene oxide; QAS: quaternary ammonium salt; GO-QAS: graphene oxide-quaternary ammonium salt; ROS: reactive oxygen species)

were significantly lower than $5 \%$, indicating that both GO and GO-QAS (at $0-200 \mu \mathrm{g} / \mathrm{mL}$ concentrations) exhibited good hemocompatibility. Such result was further evident from the optical images (Fig. 9e, inset). In addition, the hemolysis rate in the GO-QAS group was slightly higher than that in the GO group at $200 \mu \mathrm{g} / \mathrm{mL}$, which was in line with the cytotoxicity test results mentioned above. Therefore, GO-QAS at concentrations lower than $200 \mu \mathrm{g} / \mathrm{mL}$ could be identified as a biocompatible nanocomposite with no obvious cytotoxicity to mammalian cells or tendency to hemolyze erythrocytes.

\section{In vivo biosafety evaluation}

To confirm the in vitro biocompatibility findings, the in vivo biosafety of GO and GO-QAS was determined. The in vivo toxicity of nanosheets was evaluated through intravenous administration. As shown in Fig. 10, compared with the control group, it was apparent that there was no obvious cellular swelling, necrosis, hemorrhage, or congestion observed in major organs 7 days after GO and GO-QAS injection at $100 \mu \mathrm{g} / \mathrm{mL}$ concentration, which indicated that GO and GO-QAS at $100 \mu \mathrm{g} / \mathrm{mL}$ were biocompatible. Combined with the in vitro cytotoxicity and hemolysis experiment results, GO-QAS dispersion at $100 \mu \mathrm{g} / \mathrm{mL}$ could be applied for further in vivo antimicrobial evaluation.

\section{In vivo antimicrobial evaluation}

As shown in Fig. 11, for all three groups, the number of bacteria in the wound was the highest on the third day post-infection and then decreased gradually with time. On day 3 post-infection, the number of bacteria in the control group was approximately twofold higher than that in the GO group and eightfold higher than that in the GO-QAS group. Then, the number of bacteria in the GO and GOQAS groups decreased on day 5 and day 7. Compared with the GO group, the GO-QAS group had the lowest number of bacteria in the wound throughout the experiment, which indicated that the antibacterial activity of GO-QAS was stronger than that of GO in vivo.

\section{In vivo evaluation of wound healing induced by GO-QAS nanosheets}

The wound healing rate is shown in Fig. 12. On day 3 post-infection, obvious thick yellow pus was observed on the wounds of the control and GO groups. In addition, the skin around the wound was red and swollen in the control and GO groups. However, no obvious purulent discharge was found in the blank and GO-QAS groups. Furthermore, the wound closure area in the blank and GO-QAS groups was significantly larger than that of the control and GO groups. On day 5 post-infection, purulent exudates still existed in the control and GO groups. On day 7 postinfection, the percentage of the wound closure area was 78 . $7 \%, 58.9 \%, 66.4 \%$, and $77.2 \%$ in the blank, control, GO, and GO-QAS groups, respectively. No significant difference was found between the blank and GO-QAS groups on any of the days. The results indicated that GO-QAS accelerated the healing rate of infected wounds.

\section{Histological analysis of infected wounds treated with GO-QAS nanosheets}

Based on H\&E-stained sections, we found that the length of newly regenerated epidermis was significantly longer in the GO-QAS group than in the control and GO groups on days 3 and 7 post-infection, and there was little difference between the blank and GO-QAS groups (Fig. 13). Additionally, GO-QAS facilitated granulation tissue 

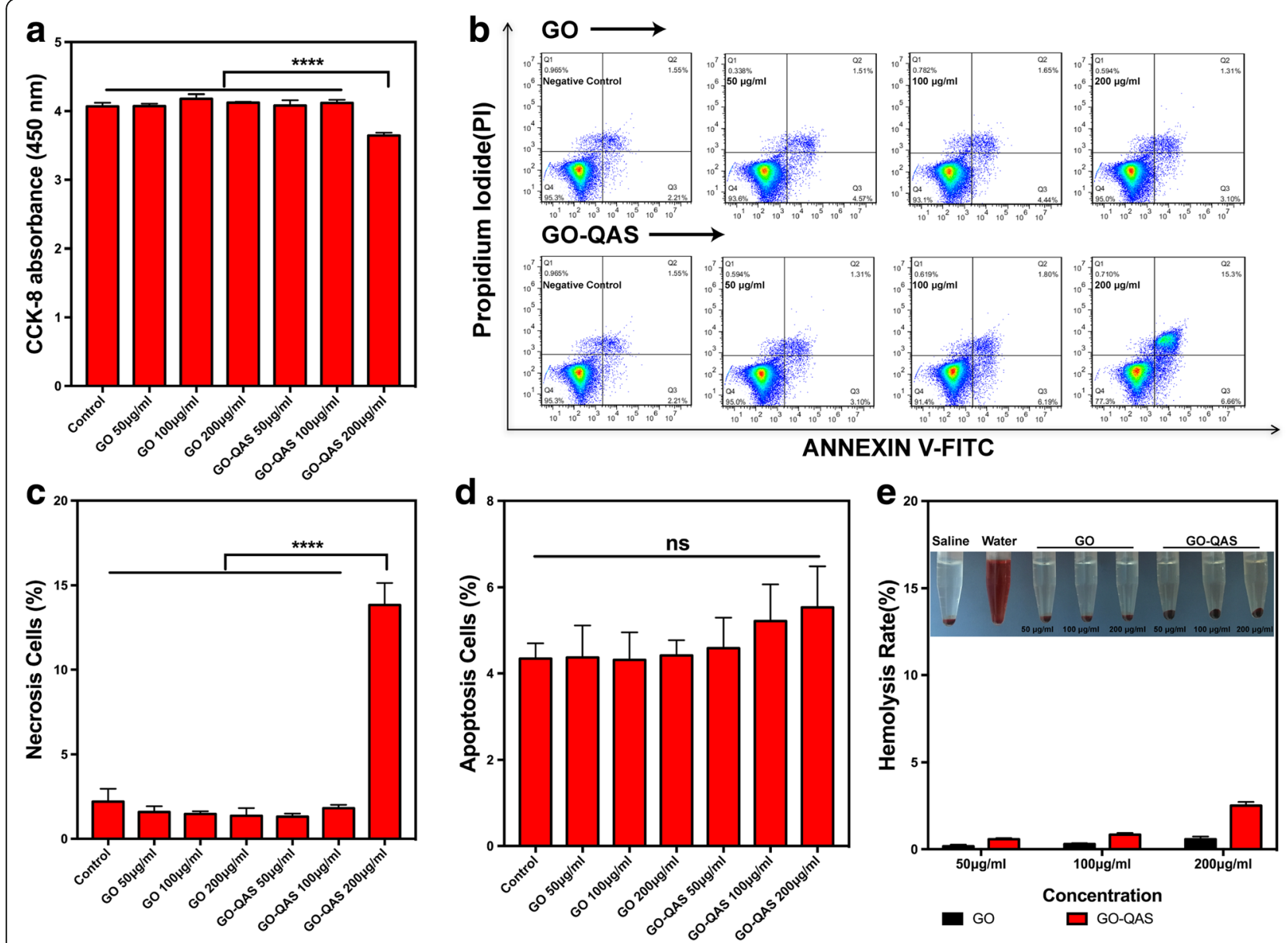

Fig. 9 a Cell viability measured using CCK-8 assay after cells being incubated with different concentrations of GO and GO-QAS suspensions for 24 h. b FACS results showing cell apoptosis and necrosis distribution after GO and GO-QAS incubation based on the Annexin V-FITC and PI assay. Statistical analysis of $\mathbf{c}$ necrosis cells ratio and $\mathbf{d}$ apoptosis cells ratio. e Hemocompatibility of GO-QAS at different concentrations. (ns represents $p>0.05$; ${ }^{* * *} p<0.0001$ ). (CCK-8: cell counting kit-8; GO: graphene oxide; GO-QAS: graphene oxide-quaternary ammonium salt; FACS: fluorescenceactivated cell sorting; PI: propidium iodide)

formation on days 3 and 7 compared with the control and GO groups. Similarly, there was little difference between the blank and GO-QAS groups in granulation tissue thickness (Fig. 14). These results indicated that GO-QAS could promote infected wound healing by accelerating reepithelialization and granulation tissue formation.

\section{Discussion}

Bacterial infection can aggravate wound deterioration, delay wound healing, and even cause sepsis and death [3]. However, the abuse of antibiotics in the past few decades has made it more difficult to eradicate pathogenic bacteria. Therefore, it is necessary to seek alternative materials to eradicate bacteria, such as nanomaterials. In recent years, GO nanosheets have been reported to exhibit excellent antibacterial activity [6]. However, graphene oxide nanosheets tend to aggregate in aqueous solutions in a layer by layer manner due to strong interplanar interactions, which limits their broad application [13]. In addition, there are also several reports claiming that GO possesses weak antimicrobial activity or even facilitates bacterial proliferation [17-19]. Thus, in this study, to confirm the antibacterial activity of GO and make it more stable in solution, a graphene oxidequaternary ammonium salt (GO-QAS) nanocomposite was synthesized through amidation reactions of carboxylic group end-capped QAS polymers with primary aminedecorated GO. The grafted QAS groups served as cationic surfactants to maintain the stability of GO nanosheets in solution and enhanced the overall antibacterial activity.

The peak changes shown in the FTIR-ATR spectra (Fig. 1c) demonstrated successful synthesis of the GO-QAS nanocomposite. Then, the GO-QAS nanocomposite was characterized with SEM, TEM, AFM, DLS, zeta potential, and TGA. The SEM images showed that GO-QAS showed a sheet-like morphology with wrinkled surfaces 


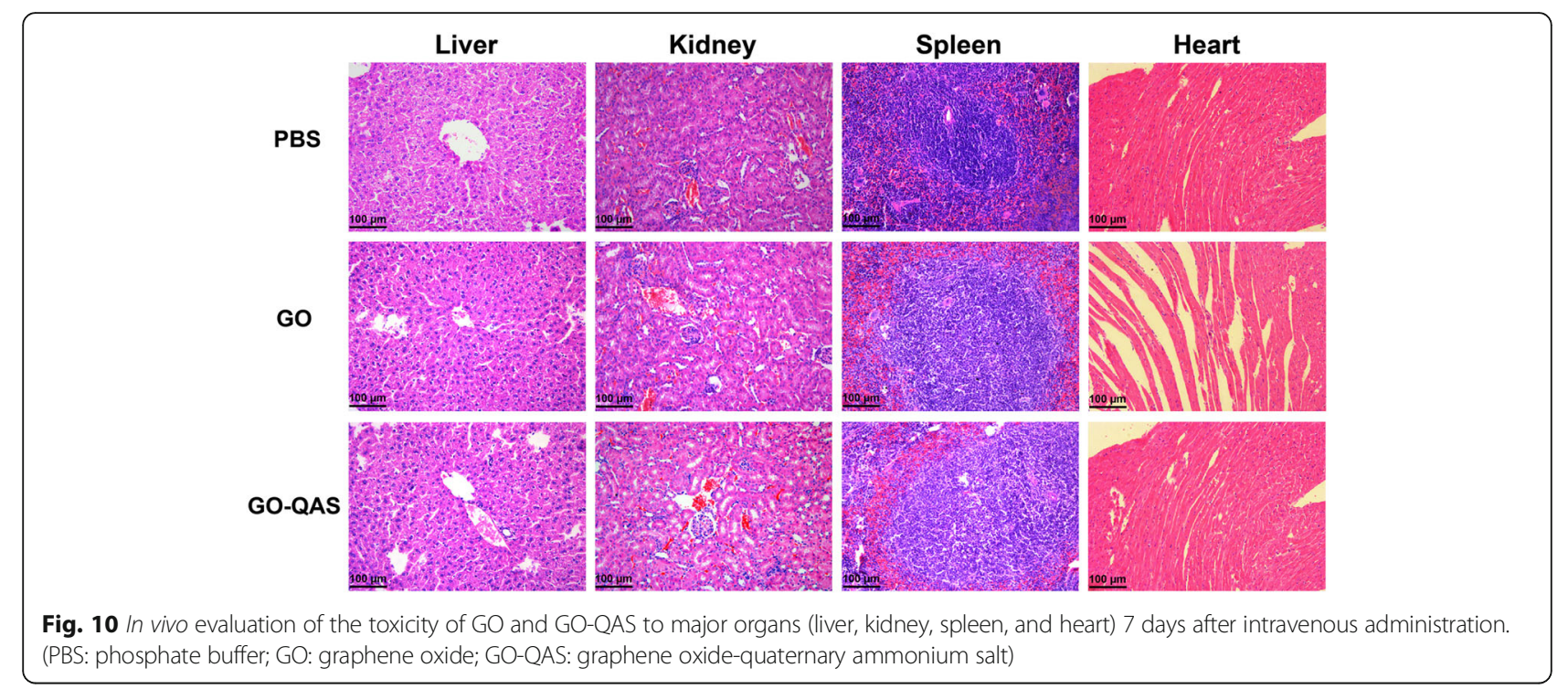

(Fig. 2a-d), which was more distinct in the TEM images (Fig. 2e-f). The AFM and DLS measurements revealed that the thickness and particle size of GO-QAS were slightly larger than that of GO (Fig.3; Fig. 4a), which was caused by the coverage of QAS on the basal plane of GO and indirectly indicated the formation of the GO-QAS nanocomposite. The zeta potential difference between GO-QAS and GO was attributed to grafting of the positively charged QAS onto the negatively charged GO nanosheets (Fig. 4b), which further demonstrated successful synthesis of the GO-QAS nanocomposite. The TGA results demonstrated that the GO-QAS nanocomposite contained 8.9 wt\% GO, $9.2 \mathrm{wt} \%$ APTMS, and $81.9 \mathrm{wt} \%$ QAS.
Since the QAS graft ratio in the GO-QAS polymer could significantly affect the antimicrobial properties, to determine the optimal QAS graft ratio at which the GOQAS nanocomposite exhibited the strongest antibacterial activity, we investigated the antibacterial activity of GOQAS with diverse QAS graft ratios. The cell viability results (Fig. 5a-b) showed that GO-QAS-3 (QAS mass fraction $=81.3 \%$ ) exhibited the optimal QAS graft ratio, which also indicated that the antibacterial effect of GO-QAS was attributed not to GO or QAS alone but to a synergistic effect of GO and QAS. Since GO-QAS-3 showed the highest antibacterial activity, GO-QAS-3 (the optimized GO-QAS) was utilized in the following experiments.

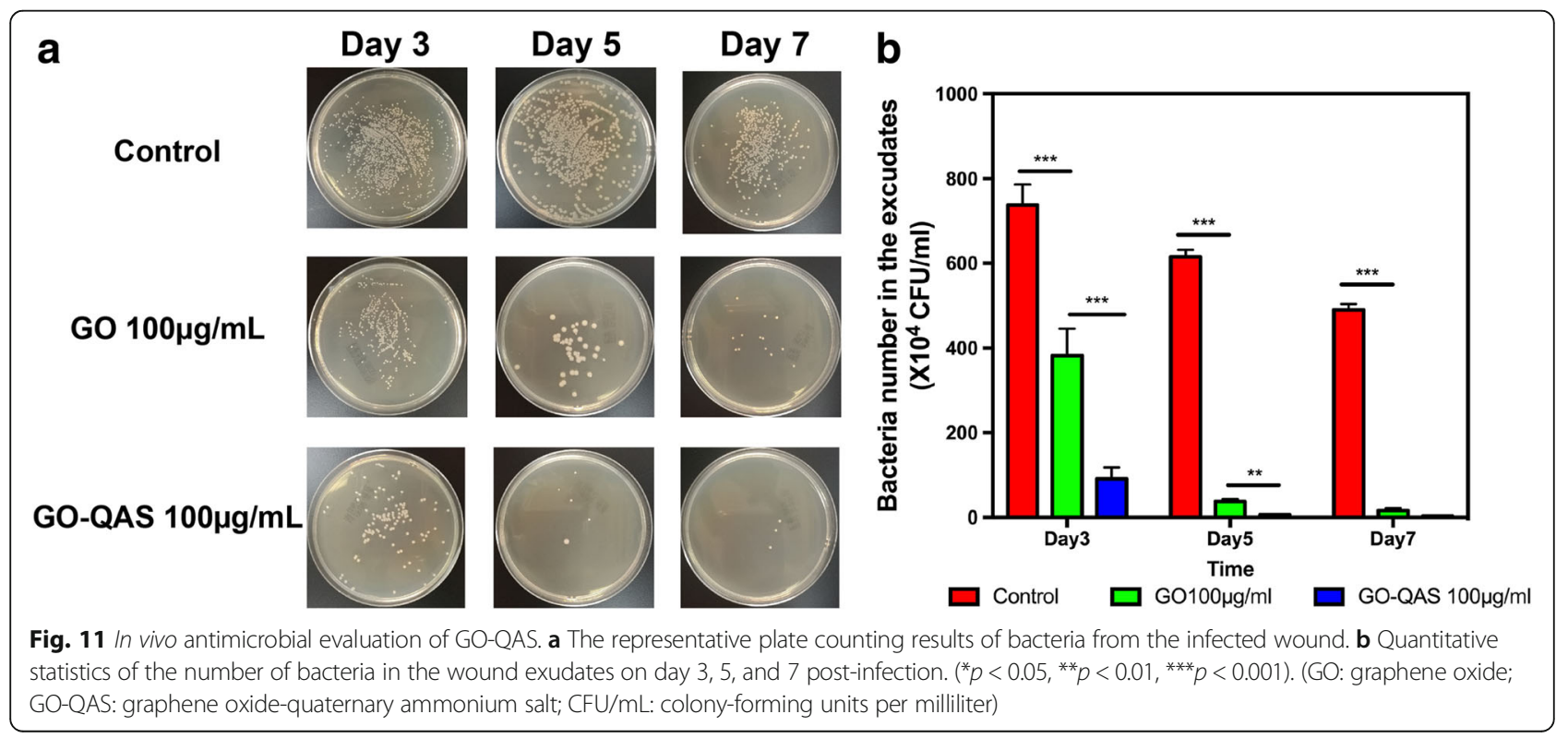




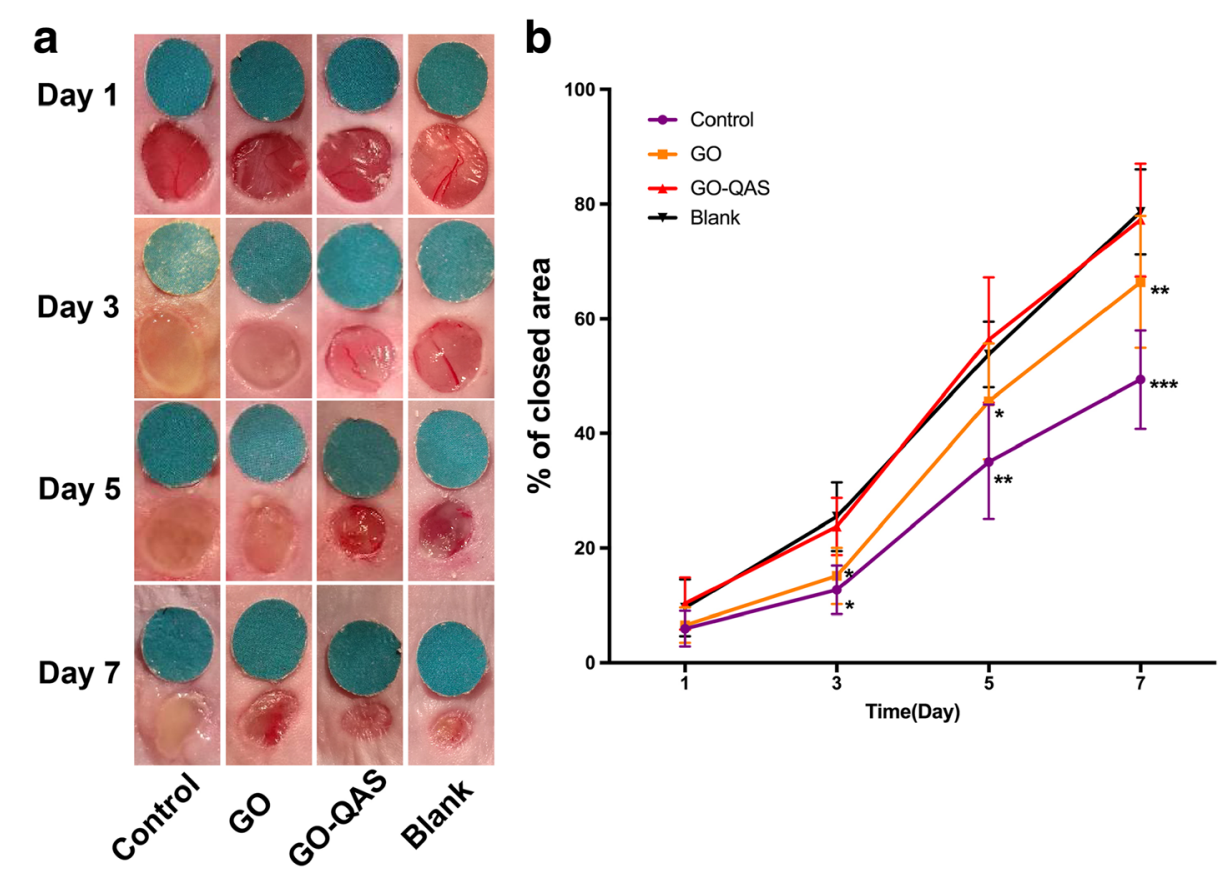

Fig. 12 The effect of GO-QAS on infected wound healing. a The representative macroscopic appearance of wound from the blank, control, GO, and GO-QAS groups. b The area of wound closure at different time points. A 6-mm-diameter standard disc was used as the reference when taking photos. The values are shown as the mean $\pm \mathrm{SD}(n=10)$. Asterisks indicated the difference between each group and GO-QAS group. $\left({ }^{*} p<0.05,{ }^{* *} p<0.01,{ }^{* * *} p<0.001\right)$. (GO: graphene oxide; GO-QAS: graphene oxide-quaternary ammonium salt)

After we determined the optimized QAS graft ratio, it was necessary for us to further detect the antibacterial properties of the optimized GO-QAS nanosheets. The results (see Additional file 1: Figure S1) showed that GO-QAS possessed visible bactericidal activity against both gram-positive and gram-negative bacteria. Interestingly, GO could not form an inhibition zone for either bacteria due to the poor diffusion property of GO on the agar plate, as previously reported [46], which might be caused by Van der Waals interactions between nanosheets. However, grafting of QAS onto GO nanosheets significantly increased the stability and dispersion properties of GO (see Additional file 1: Figure S4). It seems that the grafted QAS can weaken the interaction force between nanosheets. In addition, gram-positive bacteria were more sensitive to GO-QAS than gram-negative bacteria, since the inhibition zone was much clearer and larger, which might be because both GO and QAS were more effective against gram-positive bacteria [31]. A previous study reported that the external layers of the gram-negative bacterial cell wall, which is composed of lipopolysaccharides and proteins, can resist penetration of biocides. The cell wall of gram-positive bacteria, which is composed of peptidoglycan layers, can easily be penetrated [27]. The plate count results indicated that GO and QAS can kill both gram-positive and gramnegative bacteria but with limited antibacterial effect, while GO-QAS nanosheets significantly improved the killing efficiency (Fig. 5c-d). The bacterial live/dead viability assay results were not only in good accordance with the results obtained with the plate count method but also indicated that bacterial membranes were damaged after incubation with GO, QAS, and GO-QAS, which was further verified by observing cell morphology changes with SEM and measuring the efflux of cytoplasmic constituents (Fig. 6).

Since we have demonstrated the excellent antibacterial activity of GO-QAS, it was intriguing for us to detect whether the antibacterial activity of GO-QAS is attributed to a synergistic effect of GO and QAS or merely an additive effect of the two constituents mixed together. Bacteria were treated with GO, QAS, a mixture of GO and QAS, or GO-QAS. The antibacterial results (Fig. $5 \mathrm{e}-\mathrm{f}$ ) showed that GO-QAS exhibited higher antibacterial activity than the mixture of GO and QAS, indicating a synergistic antibacterial effect of GO and QAS. Such results could explain why there is an optimal QAS graft ratio at which GO-QAS exhibits the highest antibacterial activity. The mechanism of the synergistic antibacterial effect may be attributed to the following factors: (1) GO-QAS nanosheets have a much higher local QAS density/concentration on nanosheets compared with QAS solution and therefore could have much stronger antibacterial activity when in contact with bacteria. (2) QAS polymers could work as a surfactant to stabilize GO nanosheets in solution and prevent aggregation, which would improve the GO nanosheet 

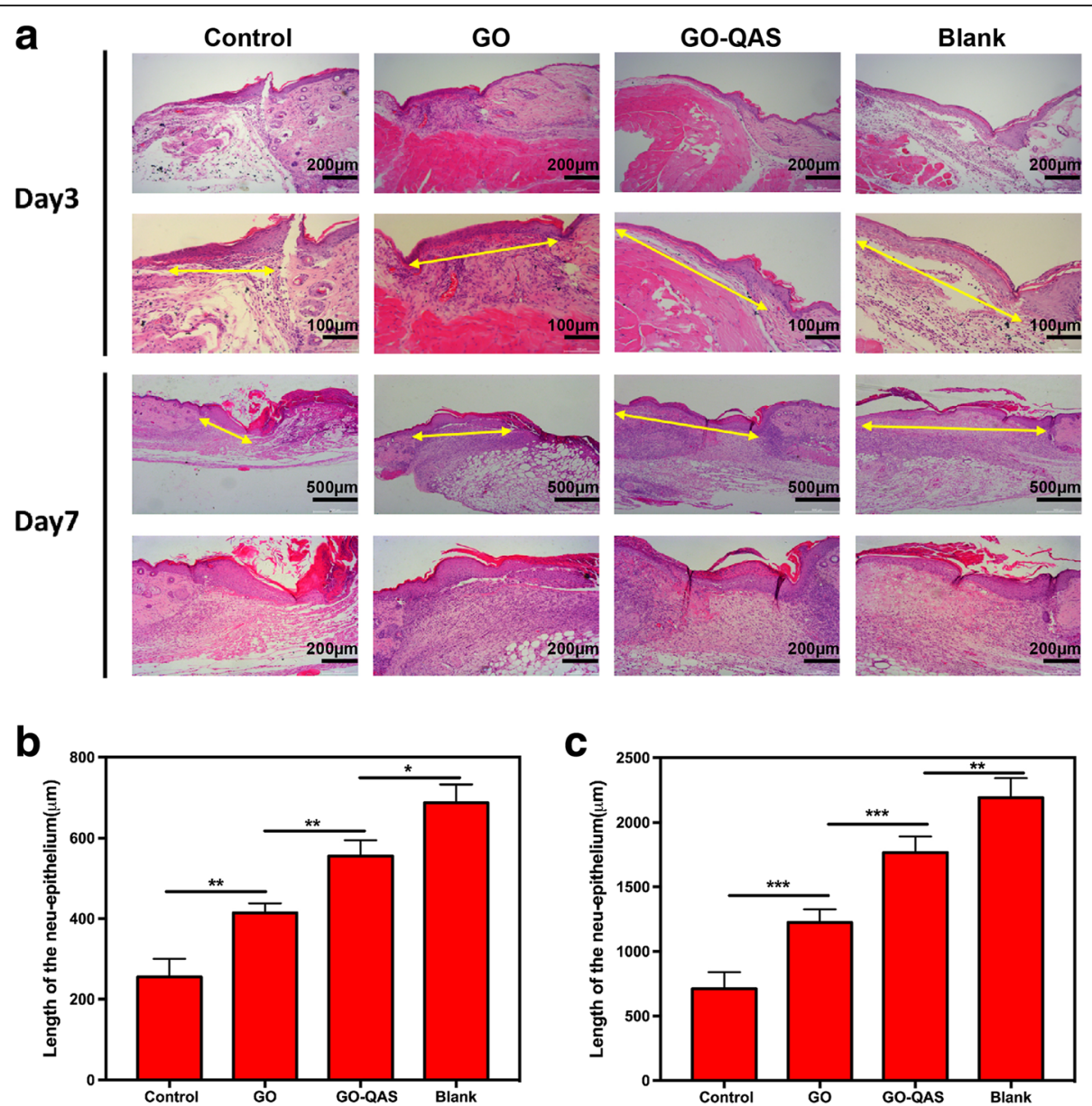

Fig. 13 The effect of GO-QAS on re-epithelialization. a Representative histological images (with hematoxylin and eosin staining) of the length of the newly formed epidermis on day 3 and 7 post-infection in the control, GO, GO-QAS, and blank groups. The yellow double-headed arrows indicate the newly formed epidermis. $\mathbf{b}$ Measurement of the length of the newly regenerated epidermis on day 3. $\mathbf{c}$ Measurement of the length of the newly regenerated epidermis on day 7 . ( ${ }^{*} p<0.05,{ }^{* *} p<0.01,{ }^{* * *} p<0.001$ ). (GO: graphene oxide; GO-QAS: graphene oxide-quaternary ammonium salt; H\&E: hematoxylin and eosin)

antibacterial performance. (3) Positively charged GO-QAS nanosheets could be more easily adsorbed onto the negatively charged surface of the bacterial membrane through electrostatic interactions. Based on the antibacterial activity of GO, QAS, and GO-QAS, we could roughly calculate the contributions of each component to the antibacterial activity of GO-QAS using the following formula: antibacterial contribution $\%=$ individual antibacterial activity/antibacterial activity of GO-QAS $\times 100 \%$. Therefore, for GO-QAS against $E$. coli, the antibacterial contributions of each part were $9 \%$ for GO and $67 \%$ for QAS. For S. aureus, the antibacterial contributions were $10 \%$ for GO and $72 \%$ for QAS.

Previous research has reported antibacterial activity of GO through membrane disruption and oxidative stress induction $[11,12]$ and the antimicrobial activity of QAS through cell membrane perturbation [25-27]. The bacterial live/dead assay results mentioned above indicated that the bacterial cell membrane was compromised after nanocomposite treatments. It was intriguing for us to determine whether GO-QAS shared the same and enhanced antibacterial mechanisms. Because gramnegative bacteria were more resistant to GO-QAS than gram-positive bacteria, we chose $E$. coli to carry out the following antibacterial mechanism experiments. SEM images of bacteria morphology (Fig. 7) indicated that GO-QAS exhibited the combined antibacterial mechanisms of GO and QAS. These results indicated a synergistic antibacterial effect of GO nanosheets and QAS, because not only did the GO-bacteria interaction contribute to the wrapping of the bacteria membrane with nanosheets, it created opportunities for full contact between grafted QAS and the cell membrane, thus increasing the local concentration of QAS on the bacteria membrane. Additionally, QAS facilitated the dispersion of GO nanosheets, thus making the interaction between GO and bacteria much easier. Moreover, 


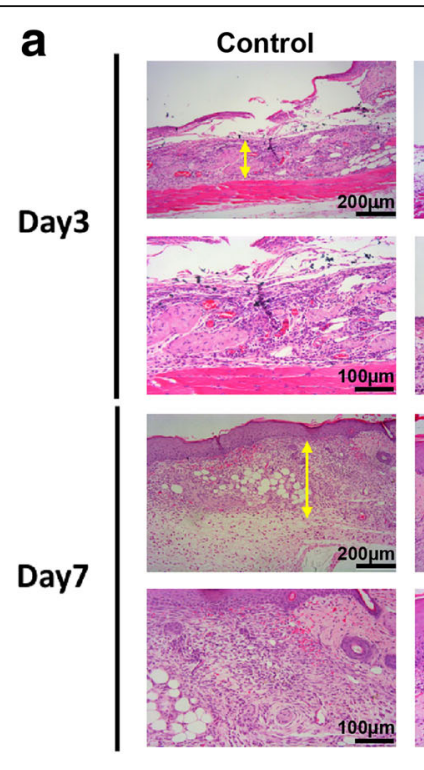

b

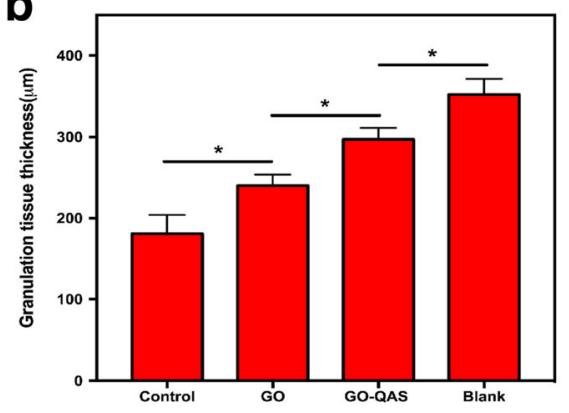

GO
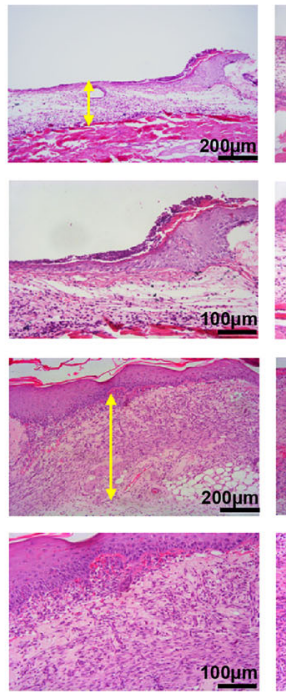
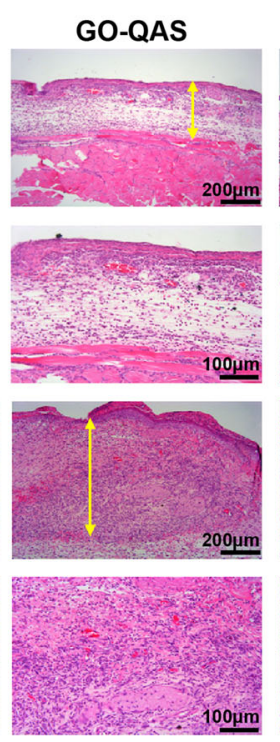

Blank
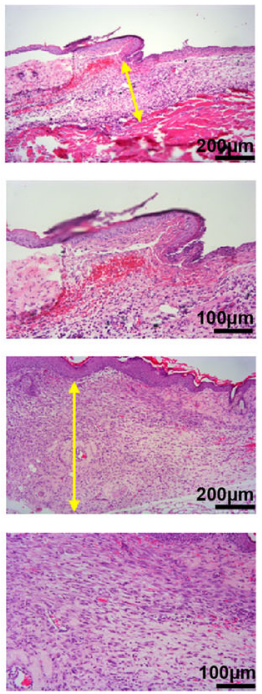

C

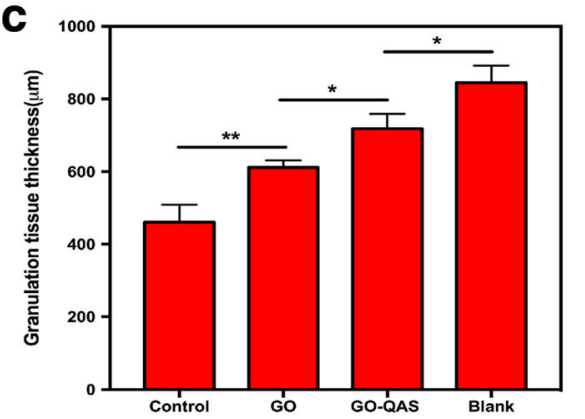

Fig. 14 The effect of GO-QAS on granulation tissue formation. a Representative histological images (with hematoxylin and eosin staining) of the granulation tissue thickness on day 3 and 7 post-infection in the Control, GO, GO-QAS, and Blank groups. The yellow double-headed arrows indicate the granulation tissue. $\mathbf{b}$ Measurement of the granulation tissue thickness on day 3 post-infection. $\mathbf{c}$ Measurement of the granulation tissue thickness on day 7 post-infection. $\left({ }^{*} p<0.05,{ }^{* *} p<0.01\right.$ ). (GO: Graphene oxide; GO-QAS: graphene oxide-quaternary ammonium salt; H\&E: hematoxylin and eosin)

although previous molecular dynamics simulations revealed that $\mathrm{GO}$ nanosheets could be spontaneously adsorbed onto a phospholipid membrane by the Van der Waals force [10], the positively charged GO-QAS nanosheets could be more easily adsorbed onto the negatively charged surface of the bacterial membrane through electrostatic interactions [47], thus causing more severe membrane damage. Bacterial membrane disruption was further demonstrated by measuring leakage of cytoplasmic material (Fig. 8a).

Oxidative stress is a highly recognized antibacterial mechanism of various carbon nanomaterials, such as graphene oxide [11, 12], fullerene [48], and carbon nanotubes (CNTs) [49]. Oxidative stress could subsequently disturb normal bacterial metabolism and cause protein denaturation, lipid peroxidation, and DNA damage, eventually leading to bacteria death [12]. The results (Fig. 8b) showed that both GO and GO-QAS could enhance the ROS level in bacteria, which corroborated previous literature reporting the antibacterial activity of graphene-based nanomaterials through ROS induction $[7,8]$. In addition, QAS could also induce ROS production, which might be due to bacterial metabolism disruption after QAS enters the cytoplasm. Remarkably, GOQAS induced higher ROS levels than GO at the same concentration, which indicated that the functional QAS group on GO could also induce ROS generation. These results revealed that GO-QAS can eradicate bacteria through oxidative stress induction.

After we demonstrated the excellent antibacterial activity of GO-QAS towards both gram-positive and gramnegative bacteria and revealed the non-specific antibacterial mechanisms of cell membrane disruption and oxidative stress induction, we decided to explore the antimicrobial property of GO-QAS against multidrug-resistant bacteria to determine whether such mechanisms worked against these bacteria. It was found that GO-QAS could significantly eradicate MRSA and MDR-AB (see Additional file 1: 
Figure S2), which indicated that the non-specific antimicrobial mechanisms (cell membrane disruption and oxidative stress induction) of GO-QAS could also be applicable to multidrug-resistant bacteria.

The excellent antimicrobial properties make it possible for GO-QAS to become a promising antibacterial agent. However, it was essential to demonstrate the biocompatibility of GO-QAS before it is utilized in the biomedical field. The cell viability test results (Fig. 9a) showed that GO-QAS at concentrations lower than $200 \mu \mathrm{g} / \mathrm{mL}$ showed no obvious cytotoxicity. These results were further demonstrated by the flow cytometry apoptosis assay (Fig. 9b-d). The results showed that GO-QAS at concentrations lower than $200 \mu \mathrm{g} / \mathrm{mL}$ caused no obvious cell apoptosis or necrosis. These results indicated that GO-QAS at concentrations lower than $200 \mu \mathrm{g} / \mathrm{mL}$ possessed good biocompatibility with mammalian cells.

Hemocompatibility is another important criterion to evaluate the biocompatibility of nanomaterials. Hemolysis should not occur when nanomaterials are used in bloodcontact applications, such as applied on wounds. According to the YY/T0127.1 standard, a hemolysis rate higher than $5 \%$ is not acceptable for clinical use [50]. The hemolysis results (Fig. 9e) indicated that GO-QAS exhibited good hemocompatibility with erythrocytes. Then, we assessed the in vivo biosafety of GO-QAS via intravenous administration of GO-QAS to mice. The in vivo toxicity results (Fig. 10) showed that GO-QAS at $100 \mu \mathrm{g} / \mathrm{mL}$ was biocompatible. Combined with the in vitro cytotoxicity and hemolysis assay results, the GO-QAS dispersion at $100 \mu \mathrm{g} / \mathrm{mL}$ could be applied for further in vivo antimicrobial evaluation.

Since we demonstrated the antimicrobial activity of GOQAS and detected the cytotoxicity of GO-QAS both in vitro and in vivo, it was imperative for us to detect the antibacterial efficiency of GO-QAS in vivo. For the in vivo antimicrobial evaluation, we chose GO-QAS at $100 \mu \mathrm{g} / \mathrm{mL}$ for the experiment because it caused no obvious toxicity to mammalian cells and organs according to the in vitro and in vivo toxicity tests results. The in vivo antibacterial results (Fig. 11) showed that compared with GO, GO-QAS still possessed excellent antibacterial activity in vivo, indicating the potential application of GO-QAS as an antibacterial agent to control wound infection.

Wound infection is one of the most threatening factors that contribute to prolonged wound healing. After demonstrating the significant antibacterial activity of GO-QAS in vivo, it was intriguing for us to further investigate whether topical application of GOQAS could accelerate the infected wound healing process by eradicating pathogenic bacteria on wounds. The wound healing rate results showed that GO-QAS could significantly promote wound healing compared with the control and GO groups (Fig. 12). This result indicated that GO-QAS could significantly promote infected wound healing by eradicating pathogenic bacteria on wounds and maintaining an aseptic wound healing environment. These results were also in good accordance with other studies, which proposed that GO-containing wound dressings could promote wound healing by eradicating bacteria on wounds [8].

Because re-epithelialization and granulation tissue formation are two essential factors that contribute to wound healing [51], it was necessary for us to measure the length of the neo-epithelium and the granulation tissue thickness through histological analysis. The histological analysis revealed that compared with the control and GO groups, the length of newly regenerated epidermis and the thickness of granulation tissue were significantly greater in the GO-QAS group (Fig. 13 and Fig. 14). These results indicated that GO-QAS could promote infected wound healing by accelerating re-epithelialization and granulation tissue formation, which was attributed to the favorable antibacterial activity and biocompatibility of GO-QAS.

\section{Conclusions}

The present study reported the synthesis of a novel antibacterial nanocomposite by grafting QAS onto GO nanosheets through surface modification and optimizing the QAS ratio. The as-prepared GO-QAS nanosheets exhibited proper biocompatibility both in vitro and in vivo. With synergistically enhanced antibacterial activity compared with pure GO, QAS, and the simple mixture of GO and QAS, the GO-QAS nanosheets exhibited highly effective antibacterial activity towards S. aureus, E. coli, and multidrug-resistant bacteria through bacterial membrane perturbation and oxidative stress induction. In addition, the GO-QAS nanocomposite maintained the natural and aseptic wound environment by eradicating pathogenic bacteria in wounds, which in turn accelerated the infected wound healing process by promoting re-epithelialization and granulation tissue formation. The overall results of this study indicated that the GO-QAS nanocomposite could be a promising antimicrobial agent for infected wound management and antibacterial wound dressing synthesis.

\section{Additional file}

Additional file 1: Table S1. The conjugated GO-QAS nanocomposites reaction yields and estimated mass fraction of GO and QAS in the nanocomposites; Figure S1. Evaluation of antibacterial activity of GO and GOQAS against E. coli and S. aureus by agar diffusion assay; Figure S2. Evaluation of the antimicrobial activity of GO-QAS against MRSA and MDR-AB; Figure S3. Plate count method results of E. coli and S. aureus after incubation with different concentrations of GO, QAS, and GO-QAS dispersions. Figure S4. Photograph of GO and GO-QAS nanosheets dispersed in different aqueous solutions without sonication. An additional file shows these data [see Additional file 1]. (DOC 10857 kb) 


\section{Abbreviations}

CCK-8: Cell counting kit-8; CFU/mL: Colony-forming units per milliliter; $E$. coli: Escherichia coli; GO: Graphene oxide; GO-QAS: Graphene oxidequaternary ammonium salt; HaCaT: Human immortalized keratinocyte; LB: Luria-Bertani; MDR-AB: Multidrug-resistant Acinetobacter baumanii; MRSA: Methicillin-resistant Staphylococcus aureus; OD: Optical density; QAS: Quaternary ammonium salt; ROS: Reactive oxygen species; S. aureus: Staphylococcus aureus

\section{Funding}

This work was financially supported by the Southwest Hospital Key Program (SWH2016ZDCX2014), National Natural Science Foundation of China (No. 81372082), National Special Scientific Projects of Public Welfare Industry Funding of China (No. 201502028), and the State Key Laboratory Funding (SKLZZ201221).

\section{Availability of data and materials}

The datasets used and/or analyzed during the current study are available from the corresponding author on reasonable request.

\section{Authors' contributions}

$J W, M X$, and $G L$ led the research. $T L$ and $Y L$ were responsible for the main experiments and wrote the manuscript. ML and GS helped with the antibacterial study. YW and WH directed the data analysis. XH and RZ helped with the cell culture. All authors read and approved the final manuscript.

\section{Ethics approva}

All the animal experiments (including in vivo biosafety, antibacterial activity, and infected wound healing evaluation) and the hemolysis assay were approved by the Institutional Animal Care and Use Committee of the Army Medical University.

\section{Competing interests}

The authors declare that they have no competing interests.

\section{Author details}

${ }^{1}$ Institute of Burn Research, State Key Laboratory of Trauma, Burn and Combined Injury, Southwest Hospital, Third Military Medical University (Army Medical University, Chongqing, China. ${ }^{2}$ Chongqing Key Laboratory for Disease Proteomics, Chongqing, China. ${ }^{3}$ Department of Mechanical Engineering, University of Manitoba, Winnipeg, MB, Canada. ${ }^{4}$ Department of Burns, The First Affiliated Hospital of Sun Yat-Sen University, Guangzhou, People's Republic of China.

\section{Received: 16 March 2018 Accepted: 11 April 2018}

\section{Published online: 21 May 2018}

\section{References}

1. Laxminarayan R, Sridhar D, Blaser M, Wang M, Woolhouse M. Achieving global targets for antimicrobial resistance. Science. 2016;353:874-5.

2. O'Neill J. Tackling Drug-Resistant Infections Globally: Final Report and Recommendations. the Review on Antimicrobial Resistance. 2016. http:// amr-review.org/sites/default/files/160525_Final\%20paper_with\%20cover.pdf. Accessed 26 Apr 2018

3. Jahromi M, Zangabad P, Basri S, Zangabad K, Ghamarypour A, Aref A, et al. Nanomedicine and advanced technologies for burns: preventing infection and facilitating wound healing. Adv Drug Deliv Rev. 2017;123:33-64.

4. Liu SB, Zeng TH, Hofmann M, Burcombe E, Wei J, Jiang RR, et al. Antibacterial activity of graphite, graphite oxide, graphene oxide, and reduced graphene oxide: membrane and oxidative stress. ACS Nano. 2011;5:6971-80

5. Ji HW, Sun HJ, Qu XG. Antibacterial applications of graphene-based nanomaterials: recent achievements and challenges. Adv Drug Deliv Rev. 2016;105:176-89.

6. Yousefi M, Dadashpour M, Hejazi M, Hasanzadeh M, Behnam B, de la Guardia M, et al. Anti-bacterial activity of graphene oxide as a new weapon nanomaterial to combat multidrug-resistance bacteria. Mater Sci Eng C. 2017;74:568-81.

7. Khan M, Abdelhamid HN, Wu HF. Near infrared (NIR) laser mediated surface activation of graphene oxide nanoflakes for efficient antibacterial, antifungal and wound healing treatment. Colloids Surf. B Biointerfaces. 2015;127:281-91.

8. Mahmoudi N, Eslahi N, Mehdipour A, Mohammadi M, Akbari M, Samadikuchaksaraei $\mathrm{A}$, et al. Temporary skin grafts based on hybrid graphene oxide-natural biopolymer nanofibers as effective wound healing substitutes: pre-clinical and pathological studies in animal models. J Mater Sci Mater Med. 2017;28:73-86.

9. Fan ZJ, Liu B, Wang JQ, Zhang SY, Lin QQ, Gong PW, et al. A novel wound dressing based on ag/graphene polymer hydrogel: effectively kill bacteria and accelerate wound healing. Adv Funct Mater. 2014;24:3933-43.

10. Szunerits S, Boukherroub R. Antibacterial activity of graphene-based materials. J Mater Chem B. 2016;4:6892-912.

11. Gurunathan S, Han JW, Dayem AA, Eppakayala V, Kim JH. Oxidative stressmediated antibacterial activity of graphene oxide and reduced graphene oxide in Pseudomonas aeruginosa. Int J Nanomedicine. 2012;7:5901-14.

12. Zou XF, Zhang L, Wang ZJ, Luo Y. Mechanisms of the antimicrobial activities of graphene materials. J Am Chem Soc. 2016:138:2064-77.

13. Liu YN, Park M, Shin HK, Pant B, Choi J, Park YW, et al. Facile preparation and characterization of poly(vinyl alcohol)/chitosan/graphene oxide biocomposite nanofibers. J Ind Eng Chem. 2014;20:4415-20.

14. Gudarzi M. Colloidal stability of graphene oxide: aggregation in two dimensions. Langmuir. 2016;32:5058-68.

15. Hegab HM, ElMekawy A, Zou L, Mulcahy D, Saint C, Ginic-Markovic M. The controversial antibacterial activity of graphene-based materials. Carbon. 2016;105:362-76.

16. Palmieri V, Carmela LM, Ciasca G, Conti C, De S, Papi M. The graphene oxide contradictory effects against human pathogens. Nanotechnology. 2017;28:152001.

17. Liu L, Liu JC, Wang YJ, Yan XL, Sun DD. Facile synthesis of monodispersed silver nanoparticles on graphene oxide sheets with enhanced antibacterial activity. New J Chem. 2011;35:1418-23.

18. de Faria A, de Moraes A, Marcato P, Martinez D, Durán N, Filho A, et al. Eco-friendly decoration of graphene oxide with biogenic silver nanoparticles: antibacterial and antibiofilm activity. J Nanopart Res. 2014; 16:2110-26.

19. Ruiz ON, Fernando K, Wang B, Brown NA, Luo PG, McNamara N, et al. Graphene oxide: a nonspecific enhancer of cellular growth. ACS Nano. 2011; 5:8100-7.

20. Kang SM, Park S, Kim D, Park SY, Ruoff RS, Lee H. Simultaneous reduction and surface functionalization of graphene oxide by mussel-inspired chemistry. Adv Funct Mater. 2011;21:108-12.

21. Li J, Zhang SW, Chen CL, Zhao GX, Yang X, Li JX, et al. Removal of Cu(II) and fulvic acid by graphene oxide Nanosheets decorated with $\mathrm{Fe}_{3} \mathrm{O}_{4}$ nanoparticles. ACS Appl Mater Interfaces. 2012;4:4991-5000.

22. Xu WP, Zhang LC, Li JP, LU Y, Li HH, Ma YN, et al. Facile synthesis of silver@graphene oxide nanocomposites and their enhanced antibacterial properties. J Mater Chem. 2011;21:4593-7.

23. de Faria A, Martinez D, Meira S, de Moraes A, Brandelli A, Filho A, et al. Antiadhesion and antibacterial activity of silver nanoparticles supported on graphene oxide sheets. Colloids Surf. B Biointerfaces. 2014;113:115-24.

24. Mao BH, Tsai JC, Chen CW, Yan SJ, Wang YJ. Mechanisms of silve nanoparticle-induced toxicity and important role of autophagy. Nanotoxicology. 2016;10:1021-40.

25. Chen CZ, Beck-tan NC, Dhurjati P, van Dyk T, LaRossa RA, Stuart L. Quaternary ammonium functionalized poly(propylene imine) dendrimers as effective antimicrobials: structure-activity studies. Biomacromolecules. 2000;1:473-80.

26. Shtyrlin NV, Sapozhnikov SV, Koshkin SA, Iksanova AG, Sabirov AH, Kayumov $A R$, et al. Synthesis and antibacterial activity of novel quaternary ammonium pyridoxine derivatives. Med Chem. 2015;11:656-65.

27. Zhang SS, Ding SP, Yu J, Chen XR, Lei QF, Fang WJ. Antibacterial activity in vitro cytotoxicity and cell cycle arrest of Gemini quaternary ammonium surfactants. Langmuir. 2015;31:12161-9.

28. Bussy C, Aliboucetta H, Kostarelos K. Safety considerations for graphene: lessons learnt from carbon nanotubes. Acc Chem Res. 2013:46:692-701.

29. Ye XL, Feng J, Zhang JX, Yang XJ, Liao XY, Shi QS, et al. Controlled release and long-term antibacterial activity of reduced graphene oxide/quaternary ammonium salt nanocomposites prepared by non-covalent modification. Colloids Surf. B Biointerfaces. 2017:149:322-9.

30. Ye XL, Qin XM, Yan XR, Guo JK, Huang LH, Chen DJ, et al. $\pi-\pi$ conjugations improve the long-term antibacterial properties of graphene oxide/ quaternary ammonium salt nanocomposites. Chem Eng J. 2016;304:873-81. 
31. Tu Q, Tian C, Ma TT, Pang L, Wang JY. Click synthesis of quaternized poly(dimethylaminoethyl methacrylate) functionalized graphene oxide with improved antibacterial and antifouling ability. Colloids Surf. B Biointerfaces. 2016;141:196-205.

32. Lai JT, Debby FA, Shea R. Functional polymers from novel carboxylterminated trithiocarbonates as highly efficient RAFT agents. Macromolecules. 2002;35:6754-6.

33. Chen JN, Peng H, Wang XP, Shao F, Yuan ZD, Han HY. Graphene oxide exhibits broad-spectrum antimicrobial activity against bacterial phytopathogens and fungal conidia by intertwining and membrane perturbation. Nano. 2014;6:1879-89.

34. Chen JN, Wang XP, Han HY. A new function of graphene oxide emerges: inactivating phytopathogenic bacterium Xanthomonas oryzae pv. Oryzae. J Nanopart Res. 2013;15:1-14.

35. Zhao RT, Lv M, Li Y, Sun MX, Kong W, Wang LH, et al. Stable nanocomposite based on PEGylated and silver nanoparticles loaded graphene oxide for long-term antibacterial activity. ACS Appli. Mater. Interfaces 2017;9: 15328-15341.

36. Mejías Carpio I, Santos CM, Wei X, Rodrigues D. Toxicity of a polymergraphene oxide composite against bacterial planktonic cells biofilms and mammalian cells. Nano. 2012;4:4746-56.

37. Zhang HZ, Zhang C, Zeng GM, Gong JL, Ou XM, Huan SY. Easily separated silver nanoparticle-decorated magnetic graphene oxide: synthesis and high antibacterial activity. J Colloid Interface Sci. 2016:471:94-102.

38. Nguyen VH, Kim BK, Jo YL, Shim JJ. Preparation and antibacterial activity of silver nanoparticles-decorated graphene composites. J Supercrit Fluids. 2012; $72: 28-35$

39. Wang XP, Liu XQ, Han HY. Evaluation of antibacterial effects of carbon nanomaterials against copper-resistant Ralstonia solanacearum. Colloids Surf B Biointerfaces. 2013;103:136-42.

40. Sasidharan A, Panchakarla LS, Chandran P, Menon D, Nair S, Rao C, et al. Differential nano-bio interactions and toxicity effects of pristine versus functionalized graphene. Nano. 2011;3:2461-4.

41. Chang YL, Yang ST, Liu JH, Dong E, Wang YW, Cao A, et al. In vitro toxicity evaluation of graphene oxide on A549 cells. Toxicol Lett. 2011;200:201-10.

42. Yang XL, Yang JC, Wang L, Ran B, Jia YX, Zhang LM, et al. Pharmaceutical intermediate-modified gold nanoparticles: against multidrug-resistant bacteria and wound-healing application via an electrospun scaffold. ACS Nano. 2017;11:5737-45.

43. Cao FF, Ju E, Zhang Y, Wang ZZ, Liu CQ, Li W, et al. An efficient and benign antimicrobial depot based on silver-infused MoS2. ACS Nano. 2017;11:4651-9.

44. Ito K, Saito A, Fujie T, Nishiwaki K, Miyazaki H, Kinoshita M, et al. Sustainable antimicrobial effect of silver sulfadiazine-loaded nanosheets on infection in a mouse model of partial-thickness burn injury. Acta Biomater. 2015;24:87-95.

45. Wang YZ, Xu R, Luo GX, Lei Q, Shu Q, Yao ZH, et al. Biomimetic fibroblastloaded artificial dermis with "sandwich" structure and designed gradient pore sizes promotes wound healing by favoring granulation tissue formation and wound re-epithelialization. Acta Biomater. 2016;30:246-57.

46. Alsharaeh E, Mussa Y, Ahmed F, Aldawsari Y, Al-Hinawi M, Sing G. Novel route for the preparation of cobalt oxide nanoparticles/reduced graphene oxide nanocomposites and their antibacterial activities. Ceram Int. 2016;42:3407-10.

47. Korupalli C, Huang CC, Lin WC, Pan WY, Lin PY, Wan WL, et al. Aciditytriggered charge-convertible nanoparticles that can cause bacteriumspecific aggregation in situ to enhance photothermal ablation of focal infection. Biomaterials. 2017;116:1-9.

48. Lyon D, Brunet L, Hinkal G, Wiesner M, Alvarez P. Antibacterial activity of fullerene water suspensions ( $\mathrm{nC60}$ ) is not due to ROS-mediated damage. Nano Lett. 2008:8:1539-43.

49. Vecitis CD, Zodrow KR, Kang S, Elimelech M. Electronic-structuredependent bacterial cytotoxicity of single-walled carbon nanotubes. ACS Nano. 2010;4:5471-9.

50. Fan MM, Zhu CL, Feng ZQ, Yang JZ, Liu L, Sun DP. Preparation of N-doped graphene by reduction of graphene oxide with mixed microbial system and its haemocompatibility. Nano. 2014;6:4882-8.

51. Wang YZ, Chen ZQ, Luo GX, He WF, Xu KG, Xu R, et al. In-situ-generated vasoactive intestinal peptide loaded microspheres in mussel-inspired polycaprolactone nanosheets creating spatiotemporal releasing microenvironment to promote wound healing and angiogenesis. ACS Appl Mater Interfaces. 2016;8:7411-21.

\section{Ready to submit your research? Choose BMC and benefit from:}

- fast, convenient online submission

- thorough peer review by experienced researchers in your field

- rapid publication on acceptance

- support for research data, including large and complex data types

- gold Open Access which fosters wider collaboration and increased citations

- maximum visibility for your research: over $100 \mathrm{M}$ website views per year

At BMC, research is always in progress.

Learn more biomedcentral.com/submissions 